\title{
Penetration and Silencing Activity of VEGF Dicer Substrate siRNA Vectorized by Chitosan Nanoparticles in Monolayer Culture and a Solid Tumor Model In Vitro for Potential Application in Tumor Therapy
}

\author{
Maria Abdul Ghafoor Raja, ${ }^{1}$ Haliza Katas, ${ }^{1}$ and Zariyantey Abd Hamid ${ }^{2}$ \\ ${ }^{1}$ Centre for Drug Delivery Research, Faculty of Pharmacy, Universiti Kebangsaan Malaysia, Jalan Raja Muda Abdul Aziz, \\ 50300 Kuala Lumpur, Malaysia \\ ${ }^{2}$ Program of Biomedical Science, School of Diagnostic and Applied Health Sciences, Faculty of Health Sciences, \\ Universiti Kebangsaan Malaysia, Jalan Raja Muda Abdul Aziz, 50300 Kuala Lumpur, Malaysia
}

Correspondence should be addressed to Haliza Katas; haliz12@hotmail.com

Received 5 April 2016; Accepted 25 July 2016

Academic Editor: Hua Zou

Copyright (c) 2016 Maria Abdul Ghafoor Raja et al. This is an open access article distributed under the Creative Commons Attribution License, which permits unrestricted use, distribution, and reproduction in any medium, provided the original work is properly cited.

\begin{abstract}
Penetration and distribution of drug through the avascular regions of human solid tumors after extravasation are crucial concerns for antitumor efficacy. To address this issue, an in vitro solid tumor model of multicellular layers (MCLs) of human colorectal cancer cells (DLD-1) was established. In an attempt to deliver Dicer substrate small interfering RNA (DsiRNA), chitosan (CS) nanoparticles have been developed for targeting vascular endothelial growth factor (VEGF) gene for tumor growth inhibition. The DsiRNA-CS nanoparticles prepared by ionic gelation method had provided maximal protection of DsiRNA in full human serum up to $48 \mathrm{~h}$ incubation. RT-PCR studies revealed significant concentration- and time-dependent knock-down of VEGF mRNA and its product due to uniform penetration of DsiRNA-CS nanoparticles throughout MCLs. Taken together, this study also demonstrated that DsiRNA-CS nanoparticles could effectively knock down VEGF gene as therapeutic target in monolayer culture or in solid tumor model for potential treatment of human colorectal carcinoma.
\end{abstract}

\section{Introduction}

RNA interference (RNAi) was first identified in C. elegans in 1998 and subsequently in mammalian cells as a posttranscriptional gene silencing mechanism [1]. Within a decade, RNAi has developed into a tool for functional molecular genetics, target gene validation in drug discovery, and a novel therapeutic strategy $[2,3]$. Small interfering RNA- (siRNA-) induced RNAi is considered to be a treatment modality for human diseases including cancers $[4,5]$. However, nonspecific effects triggered by siRNAs complicate the use of RNAi for specifically downregulating gene expression [6]. It has been recently shown that chemically synthesized DsiRNA (27 bp duplexes) is more potent than traditional siRNA (21 bp duplexes) [7]. Use of DsiRNA to trigger RNAi should result in enhanced efficacy and increased longevity of RNAi, at lower concentrations than that of siRNA [8]. Unlike siRNA, DsiRNA is bound and cleaved by Dicer and then passed into the RNAi-induced silencing complex (RISC) assembly in a sequence-specific orientation [6].

Stability in biological fluids and effective delivery constitute the main challenges for RNA-based therapeutics [9-11]. Thus, carrier or transport system is the main constituent in any in vitro/in vivo DsiRNA experiment. Despite the advantages of DsiRNA, the selection of a correct transfection agent that will proficiently protect and deliver DsiRNA to the tissues and provide a sustained release for additional processing is vital. Viral delivery systems are frequently associated with safety and immunogenicity concerns [12]. Thus, nonviral transfection systems are more attractive to researchers and 
allow for better control of siRNA concentration and more foreseeable toxicity patterns. Among the nonviral delivery carriers, chitosan (CS) is a widely used cationic polymeric gene carrier [13-15]. CS is a linear polysaccharide composed of glucosamine and $\mathrm{N}$-acetyl glucosamine residues and can be derived by the partial deacetylation of chitin [16]. CS is known to be biocompatible, minimally toxic, nonimmunogenic, and degradable by enzymes [17-20].

Human malignancies are target diseases for siRNA-based therapeutics, with a long list of potential targets related to aberrant signaling pathways in cancer cells [21]. Angiogenesis in human solid tumors has drawn much attention as a direct treatment strategy and a basis for universal chemosensitization [22]. VEGF is an important angiogenic factor associated with tumor growth and metastasis in a wide variety of solid tumors [23-25]. Three-dimensional (3D) in vitro models of human solid tumors mimic the in vivo conditions of solid tumor avascular microregions, including the 3D architecture, cell density, abundance of extracellular matrix (ECM), and cell-cell and cell-ECM communications. These models are the best in vitro models for studying spatial drug distribution as a function of tissue depth (distance from drug exposure side) and possibly drug activity in situ $[26,27]$.

In the present study, DsiRNA was successfully loaded into CS nanoparticles using the ionic gelation method. DsiRNACS nanoparticles were characterized by their particle size, zeta potential, morphology, binding and entrapment efficiency, in vitro release, cytotoxicity, cellular uptake, and gene silencing activity in $2 \mathrm{D}$ cell culture. The stability of the DsiRNA-CS nanoparticles was also determined in FBS and human serum. Moreover, a solid tumor model (3D) of DLD1 cells was successfully established in vitro. The solid tumor model was used to evaluate the penetration of VEGF DsiRNA vectorized by CS nanoparticles and its ability to inhibit tumor growth. The penetration study was performed using 6-FAMlabeled DsiRNA entrapped in CS nanoparticles against naked 6-FAM DsiRNA. Finally, their efficacy was determined by in vitro gene silencing and ELISA analysis of the solid tumor model.

\section{Material and Methods}

2.1. Materials. Low-molecular-weight $(192 \mathrm{kDa})$ CS with a 75-85\% degree of deacetylation (DD) was obtained from Sigma-Aldrich (St. Louis, MO, USA) and pentasodium tripolyphosphate (TPP) was obtained from Merck (Darmstadt, Germany). DsiRNA targeting the VEGF gene $\left[5^{\prime}-\mathrm{rGr}\right.$ GrArGrUrArCrCrCrUrGrArUrGrArGrArUrCrGrArGrUAC-3' (sense strand) and $5^{\prime}$-rGrUrArCrUrCrGrArUrCrUrCrArUrCrArGrG rGrUrA rCrUrCrCrCrA-3' (antisense strand)] of $27 \mathrm{bp}$ in length was purchased from Integrated DNA Technologies (IDT) (USA). Chinese hamster lung fibroblasts (V79) and human colorectal adenocarcinoma cells (DLD-1) were obtained from American Type Culture Collection (ATCC, USA). Human umbilical vein endothelial cells (HUVECs), Medium 200, low serum growth supplement (LSGS), Roswell Park Memorial Institute medium (RPMI) 1640, and Dulbecco's Modified Eagle's Medium (DMEM) were purchased from Gibco (USA).
PureLink RNA Mini Kit, Lipofectamine RNAiMAX, PureLink DNase, SuperScript VILO MasterMix First Strand Synthesis SuperMix for RT-PCR, and PlatinumTaq DNA Polymerase were purchased from Life Technologies (Carlsbad, USA). Hoechsct 33342 stain was obtained from Thermo Scientific Dharmacon (USA). The live/dead cell viability assay kit and human VEGF Elisa kit were purchased from Invitrogen (USA). Fluorescein-labeled siRNA and DsiRNA were purchased from IDT (USA). The collagen-coated microporous membrane $(0.4 \mu \mathrm{m}$ pore size $)$ was purchased from Invitrogen (USA). The $4 \% \mathrm{w} / \mathrm{v}$ precast agarose gel electrophoresis cassettes were purchased from Invitrogen, USA. Hematoxylin and Eosin ( $\mathrm{H} \& \mathrm{E}$ ) stains were purchased from Sigma-Aldrich (USA). The alamarBlue reagent was purchased from Invitrogen (USA).

\subsection{Methods}

2.2.1. Preparation of CS Nanoparticles. CS nanoparticles were prepared via the ionic gelation method with some modifications [28]. A series of CS solutions $(0.1 \%, 0.2 \%, 0.3 \%$, and $0.4 \% \mathrm{w} / \mathrm{v}$ ) were prepared by dissolving the required amount of CS in $2 \% \mathrm{v} / \mathrm{v}$ glacial acetic acid. TPP solution of $0.1 \% \mathrm{w} / \mathrm{v}$ was prepared by separately dissolving TPP in deionized distilled water. CS nanoparticles were prepared by adding $1.2 \mathrm{~mL}$ of the TPP aqueous solution dropwise to the CS solution $(0.1 \%, 0.2 \%, 0.3 \%$, and $0.4 \% \mathrm{w} / \mathrm{v})$ at $700 \mathrm{rpm}$ for 30 min. Centrifugation (Optima L-100 XP Ultracentrifuge, Beckman-Coulter, CA, USA) was performed at 35,000 rpm at $10^{\circ} \mathrm{C}$ for $30 \mathrm{~min}$ to collect nanoparticles.

2.2.2. DsiRNA Entrapment. To incorporate DsiRNA into CS-TPP nanoparticles, $15 \mu \mathrm{L}$ of DsiRNAs $(1.6 \mu \mathrm{g} / \mu \mathrm{L})$ was added to $1.2 \mathrm{~mL}$ of TPP aqueous solution $(0.1 \% \mathrm{w} / \mathrm{v})$, and this was added to $3 \mathrm{~mL}$ of CS solution $(0.1 \%, 0.2 \%, 0.3 \%$, and $0.4 \% \mathrm{w} / \mathrm{v})$ under constant magnetic stirring $(700 \mathrm{rpm})$ at $25^{\circ} \mathrm{C}$. The particles were then left at $25^{\circ} \mathrm{C}$ for another $30 \mathrm{~min}$ before further analysis.

2.2.3. Preparation of MCLs. DLD-1 cells were maintained in RPMI-1640 and supplemented with 5\% pen-strep and $10 \%$ heat-inactivated FBS in a humidified, $5 \%(\mathrm{v} / \mathrm{v}) \mathrm{CO}_{2}$ atmosphere at $37^{\circ} \mathrm{C}$. Cells were grown on collagen-coated microporous $(0.4 \mu \mathrm{m})$ membranes in transwell inserts with a plating density of $3 \times 10^{5}$ cells/100 $\mu \mathrm{L}$ [29].

The transwell inserts containing $2 \mathrm{~mL}$ of complete RPMI1640 medium in each insert were placed in a 6-well plate containing $2.5 \mathrm{~mL}$ of complete RPMI-1640 medium in each well, followed by occasional agitation [30]. The RPMI1640 medium was replaced with fresh RPMI-1640 complete medium daily. After 6 days of culturing, MCLs were obtained. MCL thickness was measured using an optical microscope (Olympus, Japan). Each transwell insert was transferred to a new 6-well plate containing $5 \mathrm{~mL}$ of RPMI-1640 complete medium in each well for subsequent exposure to DsiRNA and DsiRNA-CS nanoparticles. Briefly, the transwell inserts were supplemented with $2 \mathrm{~mL}$ of complete RPMI-1640 medium in which naked DsiRNA/DsiRNA-Lipofectamine (negative/ positive control) and DsiRNA-CS nanoparticles were added 
to the RPMI-1640 medium for direct exposure with MCLs. The 6-well plates were maintained in an incubator with a humidified atmosphere containing $5 \% \mathrm{CO}_{2}$ at $37^{\circ} \mathrm{C}$ and supplemented with complete RPMI-1640 medium throughout the duration of the experiment.

\subsubsection{In Vitro Characterization of DsiRNA-CS Nanoparticles}

Determination of Particle Size, Zeta Potential, and Polydispersity Index (PDI). The mean particle diameter (z-average), polydispersity index (PDI), and zeta potential (surface charge) of freshly prepared CS nanoparticles were determined by photon correlation spectroscopy (PCS) using a ZS-90 Zetasizer (Malvern Instruments, Worcestershire, UK). All measurements were performed after the samples were harvested by centrifugation and resuspended in deionized distilled water. Each sample was assayed in triplicate at $25^{\circ} \mathrm{C}$, and data are reported as mean \pm standard deviation.

Morphological Analysis. Morphological characterization of DsiRNA-CS nanoparticles was carried out using transmission electron microscopy (TEM) (Tecnai Spirit, FEI, Eindhoven, The Netherlands) and AFM NTEGRA Prima (NT-MDT, Russia).

Entrapment Efficiency. The entrapment efficiency of DsiRNA (\% entrapped) was measured using a UV-vis spectrophotometer (Shimadzu UV-1800, Shimadzu Scientific Instruments, Japan) at $260 \mathrm{~nm}$. Briefly, the free DsiRNA in the supernatant recovered from centrifugation $\left(13,000 \times \mathrm{g}\right.$ at $10^{\circ} \mathrm{C}$ for $30 \mathrm{~min}$ ) was quantified by measuring its absorbance at a wavelength of $260 \mathrm{~nm}$ with a dual beam UV-vis spectrophotometer. The concentration of free DsiRNA was determined using Beer's Law $\left(A_{260} \mathscr{E} C L\right)$ where $C$ is the concentration of DsiRNA, $A_{260}$ is the absorbance at $260 \mathrm{~nm}, \mathscr{E}$ is the extinction coefficient, and $L$ is the path length of the cuvette. Extinction coefficient of DsiRNA is $518500 \mathrm{~L} \mathrm{~mol}^{-1} \mathrm{~cm}^{-1}$ and entrapment efficiency was calculated using the following formula:

$$
\begin{aligned}
& \text { Entrapment efficiency (\%) } \\
& \qquad=\left[\frac{\left(C_{\text {sample }}-C_{\text {supernatant }}\right)}{C_{\text {sample }}}\right] \times 100,
\end{aligned}
$$

where $C_{\text {sample }}$ is the concentration of DsiRNA added and $C_{\text {supernatant }}$ is the concentration of DsiRNA in the supernatant. All measurements were performed in triplicate, and data are reported as mean $\pm \mathrm{SD}$.

Gel Retardation Assay. The binding efficiency of DsiRNA to CS nanoparticles was determined using $4 \% \mathrm{w} / \mathrm{v}$ agarose gel electrophoresis and SYBR ${ }^{\circledR}$ Green (Invitrogen, Carlsbad, CA, USA) staining. Twenty microliters of sample (prepared at various CS concentrations) containing $0.15 \mu \mathrm{g}$ of DsiRNA was loaded into the wells.

Heparin Displacement Assay. Heparin sodium $(10 \mathrm{mg} / \mathrm{mL})$ was added into DsiRNA-CS nanoparticles suspended in deionized distilled water (containing $0.6 \mu \mathrm{g}$ of DsiRNA).
The mixture was incubated at $25^{\circ} \mathrm{C}$ for $1 \mathrm{~h}$ to displace DsiRNA from CS-TPP nanoparticles. The binding affinity was observed by $4 \% \mathrm{w} / \mathrm{v}$ gel electrophoresis. Electrophoresis was performed for $30 \mathrm{~min}$ at $110 \mathrm{~V}$ and DsiRNA bands were visualized under a real-time UV transilluminator at $480 \mathrm{~nm}$ (Invitrogen, Carlsbad, CA, USA).

\subsubsection{Stability Studies}

Serum Protection Assay (FBS and Human Serum). This assay and the following experiments were performed for DsiRNA-CS nanoparticles prepared with a CS concentration of $0.3 \% \mathrm{w} / \mathrm{v}$. This concentration was selected because of the desired characteristics (small nanosize, net positive charge, high entrapment efficiency, and binding efficiency) exhibited by the resultant particles. A volume of $200 \mu \mathrm{L}$ of DsiRNA-CS nanoparticles was incubated at $37^{\circ} \mathrm{C}$ with an equal volume of RPMI supplemented with 10\% FBS. Naked DsiRNA acted as a control and was treated in the same manner. At each predetermined time interval ( 0 and $30 \mathrm{~min}$ and 2, 4, 24, and $48 \mathrm{~h}), 40 \mu \mathrm{L}$ of the mixture was removed and stored at $-20^{\circ} \mathrm{C}$ to stop the reaction. Prior to gel electrophoresis, the samples were incubated in a bath incubator at $60^{\circ} \mathrm{C}$ for $3 \mathrm{~min}$ to terminate serum activity. A volume of $5 \mu \mathrm{L}$ of heparin $(1000 \mathrm{U} / \mathrm{mL})$ was then added to displace DsiRNA from the CS nanoparticles. The structure integrity of DsiRNA displaced from nanoparticles was then analyzed by gel electrophoresis with $4 \% \mathrm{w} / \mathrm{v}$ agarose gel stained with SYBR Green (Invitrogen, Carlsbad, CA, USA). Moreover, a human serum protection assay was also performed in which $200 \mu \mathrm{L}$ of DsiRNA-CS nanoparticles was incubated with an equal volume of human serum at $37^{\circ} \mathrm{C}$. Naked DsiRNA was used as a control.

Quantification of DsiRNA. DsiRNA bands obtained from the serum protection assay were quantified using ImageJ software, developed by the National Institutes of Health (NIH) (Maryland, US). The mean area, percent, and relative density of each band were determined using the software.

Storage Stability. DsiRNA-CS nanoparticles were suspended in deionized distilled water/PBS and stored at 4 and $25^{\circ} \mathrm{C}$ for 15 days. The storage stability of the nanoparticles was determined by measuring their particle size at predetermined time points. Deionized distilled water was used in this experiment in order to investigate the stability of nanoparticles in their resuspending medium. This was performed to help identify a strategy for stabilizing the particles.

2.2.6. In Vitro Release Studies. The release profile of the DsiRNA-CS nanoparticles was studied in PBS at $\mathrm{pH}$ 7.4. Samples $(4 \mathrm{~mL})$ were centrifuged at $35,000 \mathrm{rpm}$ for $30 \mathrm{~min}$ at $25^{\circ} \mathrm{C}$, and the pellets were resuspended in PBS $(3 \mathrm{~mL})$ at $\mathrm{pH}$ 7.4. The mixture was placed on magnetic stirrer with a stirring speed of $100 \mathrm{rpm}$ at $37^{\circ} \mathrm{C}$ for 15 days. At predetermined time intervals, samples were centrifuged at $35,000 \mathrm{rpm}$ for $30 \mathrm{~min}$ at $25^{\circ} \mathrm{C}$. Then, a whole volume of supernatant was taken for analysis and replaced with an equivalent volume of fresh buffer solution. The amount of DsiRNA released in 
the supernatant was analyzed by a UV-vis spectrophotometer (Shimadzu 1800) at a wavelength of $260 \mathrm{~nm}$.

2.2.7. Cytotoxicity Studies. The V79 cell line (ATCC, Manassas, VA, USA) was cultured in DMEM supplemented with $10 \%$ FBS and $1 \%$ pen-strep at a seeding density of $2 \times 10^{4}$ cells per well. The DLD-1 cells (ATCC, Manassas, VA, USA) were cultured in RPMI-1640 medium supplemented with 10\% FBS and $1 \%$ pen-strep at a seeding density of $4 \times 10^{4}$ cells per well. Moreover, the HUVECs (Gibco, USA) were cultured in medium 200 at a seeding density of $3 \times 10^{4}$ cells per well. The HUVECs were supplemented with $10 \%$ LSGS and $1 \%$ penstrep. All cells were incubated with DsiRNA-CS nanoparticles for 24 and $48 \mathrm{~h}$.

After 24 and $48 \mathrm{~h}$ incubation of samples with cells, a final dilution of $1 / 10$ per cell volume of alamarBlue reagent was added to the treated cells, followed by incubation for $4 \mathrm{~h}$ prior to analysis. The absorbance of each sample at $570 \mathrm{~nm}$ (A570) was measured using a microplate reader (Varioskan Flash, Thermo Scientific, Waltham, MA, USA). All cells were maintained at $37^{\circ} \mathrm{C}$ in a humidified $5 \% \mathrm{CO}_{2} / 95 \%$ air atmosphere.

Cell viability of all the samples was determined using the following equation:

$$
\text { Cell viability }(\%)=\left(\frac{\mathrm{A} 570 \text { of treated cells }}{\mathrm{A} 570 \text { of control cells }}\right) \times 100 \text {. }
$$

2.2.8. LIVE/DEAD Cell Viability Assay. A cell viability assay was performed to measure the functional status of the cells by detecting cytoplasmic esterase activity using the LIVE/DEAD Viability/Cytotoxicity kit for mammalian cells (Invitrogen, Carlsbad, CA, USA). The kit contains calcein, which stains living cells (green), and ethidium bromide, which stains dead cells (red). This assay was performed in 96-well plates. Briefly, DLD-1 cells were plated at a seeding density of $4 \times 10^{4}$ cells per well. The cells were supplemented with $10 \%$ FBS and $1 \%$ pen-strep and maintained at $37^{\circ} \mathrm{C}$ in a humidified $5 \% \mathrm{CO}_{2} / 95 \%$ air atmosphere. The cells were treated with DsiRNA-CS nanoparticles for 24 and $48 \mathrm{~h}$. Subsequently, the cells were rinsed twice with PBS, followed by adding fluorochromes (calcein/ethidium bromide). The cells were treated with DsiRNA-CS treated with DsiRNACS nanoparticles for 24 and $48 \mathrm{~h}$ and incubating for $45 \mathrm{~min}$. The reagents were removed by rinsing with PBS followed by analysis using a Floid Cell Imaging Station (Molecular Probes Life Technology, France).

2.2.9. Cellular Internalization. DLD-1 cells $\left(4 \times 10^{4}\right)$ were seeded in a 6-well tissue culture plate and incubated for $24 \mathrm{~h}$ ( $80 \%$ confluence). The cells in each well were incubated for $4 \mathrm{~h}$ in a medium with $10 \% \mathrm{FBS}$ at $37^{\circ} \mathrm{C}$ with free 6-FAMDsiRNA or with DsiRNA-CS nanoparticles. After incubation, the cells were washed twice with PBS and then stained with $1 \mu \mathrm{g} / \mathrm{mL}$ of Hoechst stain 33342 for $15 \mathrm{~min}$ at $37^{\circ} \mathrm{C}$. Cellular internalization of DsiRNA was examined using a Floid Cell Imaging Station (Molecular Probes Life Technology, France).

\subsubsection{In Vitro Gene Silencing}

Investigation of VEGF mRNA Suppression Using RT-PCR. To evaluate the gene silencing activity of DsiRNA-CS nanoparticles in comparison to controls, DLD-1 cells were seeded with $2 \mathrm{~mL}$ of RPMI 1640 containing $10 \%$ FBS on a 6-well plate at $5 \times 10^{4}$ cells/well. After $24 \mathrm{~h}$, samples and controls were added with fresh medium (80 pmol DsiRNA) and incubated for another $24 \mathrm{~h}$. The cells were then harvested and RNA was extracted using a PureLink RNA Mini Kit and PureLink DNase, as recommended by the manufacturer (Life Technologies, Carlsbad). In this experiment, samples consisted of a negative control (Lipofectamine and scrambled DsiRNA), positive control (Lipofectamine and VEGF DsiRNA), and DsiRNA-CS nanoparticles. The concentration of DsiRNA was kept constant in all formulations.

After obtaining RNA from the cells, the quality of RNA was assessed by $1 \% \mathrm{w} / \mathrm{v}$ agarose gel electrophoresis at $90 \mathrm{~V}$ for $60 \mathrm{~min}$ in Tris-acetate-EDTA (TAE) buffer and visualized by ethidium bromide staining. RNA was quantified using the Infinite 200 PRO NanoQuant (Tecan, Switzerland). The gel images were taken by an image reader (Fujifilm LAS-3000, Tokyo, Japan). In the next step, complementary DNA (cDNA) was prepared from $1.5 \mu \mathrm{g}$ total RNA by reverse transcription using SuperScript VILO Master Mix (Life Technologies, Carlsbad) for RT-PCR according to the manufacturer's instructions. For the VEGF gene, the forward and reverse primers were $5^{\prime}$-AGTGGTCCCAGGCTGCAC-3' and $5^{\prime}$ TCCATGAACTTCACCACTTCGT- $3^{\prime}$, respectively, whereas for the reference gene, GAPDH, the forward and reverse primers were $5^{\prime}$-ACCACAGTCCATGCCATCAC- $3^{\prime}$ and $5^{\prime}$ TCCACCACCCTGTTGCTGTA-3', respectively (1st Base, Singapore). The RT-PCR was carried out in an Eppendorf Mastercycler Nexus Gradient Thermal Cycler (Hamburg, Germany). Amplification products were resolved by $1 \% \mathrm{w} / \mathrm{v}$ agarose gel electrophoresis at $90 \mathrm{~V}$ for $60 \mathrm{~min}$ in TAE buffer and visualized by ethidium bromide staining. The images of the gel were taken by an image reader (Fujifilm LAS-3000, Tokyo, Japan). The densitometric analysis was performed using imageJ software.

Morphology and Thickness of MCLs. The morphology of the collagen layer and MCLs was observed using scanning electron microscopy (SEM). Cross-vertical sections $(10 \mu \mathrm{m})$ of MCLs were stained with $\mathrm{H} \& \mathrm{E}$ and observed under an optical microscope. Thickness of MCLs was measured by using the optical microscope software. All measurements were performed in triplicate, and data are reported as mean \pm SD.

Gene Silencing within MCLs. MCLs were exposed to naked DsiRNA and DsiRNA-CS nanoparticles (DsiRNA concentrations of 20 and $80 \mathrm{pmol}$ ) for 24 and $48 \mathrm{~h}$ at $37^{\circ} \mathrm{C}$ in a humidified $5 \% \mathrm{CO}_{2} / 95 \%$ air atmosphere. At the end of the exposure time, MCLs with collagen membranes attached were cut out of the transwell inserts using a surgical blade (size number 10), fixed with $4 \%$ paraformaldehyde, and embedded in paraffin wax and later stained with $\mathrm{H}$ \& E. Cross-vertical sections $(10 \mu \mathrm{m})$ were observed using an optical microscope. 
TABLE 1: Particle size, PDI, and zeta potential of DsiRNA-CS nanoparticles prepared at different CS concentrations, $n=3$.

\begin{tabular}{lccr}
\hline CS concentration $(\% \mathrm{w} / \mathrm{v})$ & Particle size $(\mathrm{nm}) \pm \mathrm{SD}$ & PDI \pm SD & Zeta potential $(\mathrm{mV}) \pm$ SD \\
\hline 0.1 & $126.37 \pm 15.52$ & $0.30 \pm 0.05$ & $+30.50 \pm 2.55$ \\
0.2 & $180.00 \pm 18.78$ & $0.35 \pm 0.18$ & $+37.13 \pm 2.01$ \\
0.3 & $230.23 \pm 13.80$ & $0.40 \pm 0.05$ & $+40.27 \pm 4.07$ \\
0.4 & $336.50 \pm 11.38$ & $0.55 \pm 0.02$ & $+55.30 \pm 3.91$ \\
\hline
\end{tabular}

SD, standard deviation; $n$, sample number.

ELISA Analysis of VEGF Protein in Medium. MCLs were exposed to naked DsiRNA, Lipofectamine-DsiRNA, and DsiRNA-CS nanoparticles for 24 and $48 \mathrm{~h}$ in cell culture conditions. In each sample, the concentration of DsiRNA used was $80 \mathrm{pmol}$. At the end of the exposure time, the culture medium in the bottom chamber was collected and centrifuged to remove cell debris. The amount of VEGF secreted from the MCLs was determined using the Quantikine ${ }^{\circledR}$ human VEGF immunoassay kit (Ambion, USA), according to the manufacturer's instructions. All measurements were performed in triplicate and data are reported as mean \pm SD.

DsiRNA Distribution within MCLs. MCLs were exposed to DsiRNA by adding naked 6-FAM-labeled DsiRNA (control) and DsiRNA-CS nanoparticles ( $80 \mathrm{pmol})$ to the transwell and incubated for 24 and $48 \mathrm{~h}$. At the end of incubation, cells were rinsed with PBS ( $\mathrm{pH} 7.4$ ) and fixed with $4 \%$ paraformaldehyde for $1 \mathrm{~h}$. Thereafter, samples were embedded in liquid nitrogen-cooled optimal cutting temperature compound (Tissue-Tek $^{\circledR}$, Miles Laboratories, USA). Then, $20 \mu \mathrm{m}$ thick cross-vertical sections of MCLs were prepared using a cryostat (Leica CM1900, Wetzlar, Germany). The slides were mounted using polyvinyl alcohol mounting medium with 1,4-diazabicyclo[2.2.2] octane and a cover slip. The DsiRNA distribution was observed by fluorescence microscope (Carl Zeiss, Germany).

2.3. Statistical Analysis. Data was presented as mean \pm SD. The data were analyzed using independent $t$-test or analysis of variance (One-way ANOVA, followed by Tukey post hoc analysis) using SPSS 20.0 (SPSS Inc., Chicago, IL). Values of $p<0.05$ indicated statistical significance between the groups tested.

\section{Results}

3.1. Particle Size, PDI, Zeta Potential, and Morphology. The mean particle size of DsiRNA-CS nanoparticles was significantly increased by increasing the CS concentration from $0.1 \%$ to $0.4 \% \mathrm{w} / \mathrm{v}$ (Table 1 ). All the nanoparticles had a low to moderate PDI value in the range of 0.30 to 0.55 , varying with CS concentration. This could be explained by the process of DsiRNA association during the preparation of CS nanoparticles. DsiRNA and TPP were mixed together to produce a solution that was later added dropwise to CS solution. This technique was expected to provide a better condition for efficient and controllable incorporation of DsiRNA into CS nanoparticles which yielded smaller particles. This finding is in accordance with previous reports $[31,32]$.
The zeta potential of DsiRNA-CS nanoparticles increased with increasing CS concentration at a constant DsiRNA concentration as shown in Table 1. Unloaded CS-nanoparticles had zeta potentials in the range of $+30.0 \pm 1.0$ to $+59.7 \pm$ 0.5 (Table S1 in Supplementary Material available online at http://dx.doi.org/10.1155/2016/7201204) when CS concentration ranged from $0.1 \%$ to $0.4 \% \mathrm{w} / \mathrm{v}$. However, these values were not significantly decreased when DsiRNA was entrapped into the nanoparticles. This could be due to the small number of DsiRNA phosphate groups that were available to interact with $\mathrm{CS} \mathrm{NH}_{3}{ }^{+}$groups. Particle size of DsiRNA loaded nanoparticles was smaller compared to unloaded ones that could be attributed by better interactions between CS polymers and TPP in the presence of DsiRNA even in a small number of phosphate groups. In comparison to siRNA, the larger size of the DsiRNA duplex (27 mer, MW 16,558 g/mol) could be attributed to the small number of available negatively charged phosphate groups to compensate for $\mathrm{NH}_{3}{ }^{+}$ groups of CS [33]. This explains the finding that DsiRNA loading had less of an effect on the overall surface charge of CS nanoparticles. This effect might be due to a large amount of DsiRNA buried in the matrices of CS nanoparticles by the entrapment method, resulting in less density of negative charge.

AFM micrographs of DsiRNA-CS nanoparticles prepared from $0.3 \% \mathrm{w} / \mathrm{v}$ CS revealed a spherical morphology (Figures 1(a) and 1(b)). Moreover, spherical morphology was also observed for DsiRNA-CS nanoparticles prepared at different CS concentrations using TEM as depicted in Figures 1(c), $1(\mathrm{~d}), 1(\mathrm{e})$, and 1(f). Thus, the results suggested that different CS concentrations and DsiRNA entrapment had no effect on the morphology of CS nanoparticles. The spherical shape of DsiRNA-CS nanoparticles could be governed by the electrostatic interactions between DsiRNA and CS as well as between TPP and CS, provided for controllable gelation of CS.

3.2. DsiRNA Entrapment and Binding Efficiencies. A higher DsiRNA entrapment efficiency was obtained (92\% to $100 \%$ ) for CS nanoparticles when CS concentration was increased from $0.1 \%$ to $0.4 \% \mathrm{w} / \mathrm{v}$ as measured by UV-vis spectrophotometry and shown in Figure 2(a). Entrapment efficiency of DsiRNA into CS nanoparticles was therefore influenced by CS concentration. Higher entrapment efficiency was achieved due to stronger electrostatic attraction between DsiRNA molecules with a higher density of oppositely charged CS.

Strong binding between DsiRNA and CS nanoparticles was observed (due to the absence of a trailing band), as shown in Figure 2(b). Absence of a band indicated immobilization of DsiRNA, which was probably due to efficient entrapment 


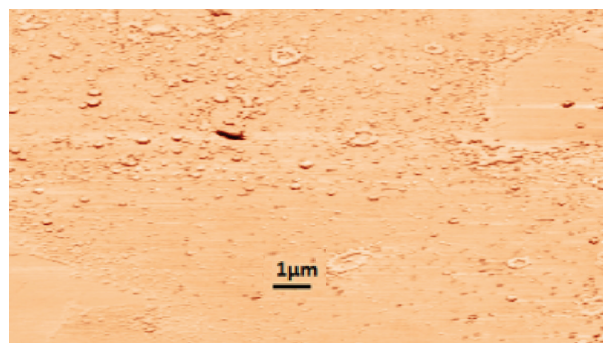

(a)

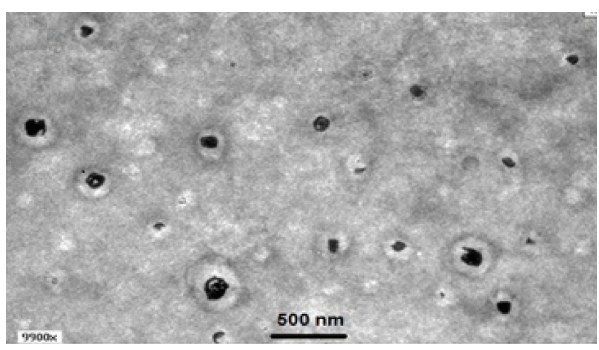

(c)

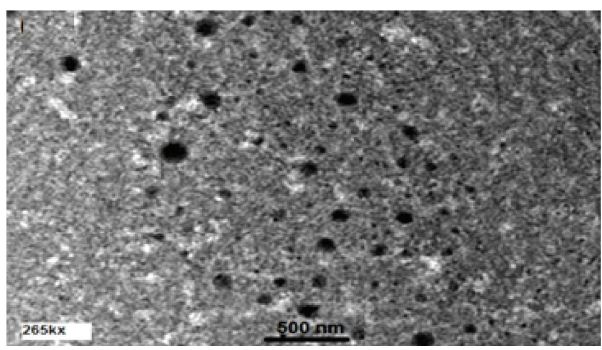

(e)

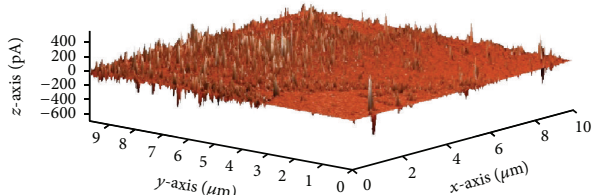

(b)

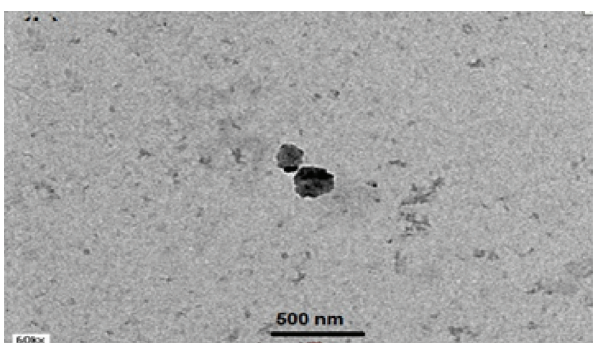

(d)

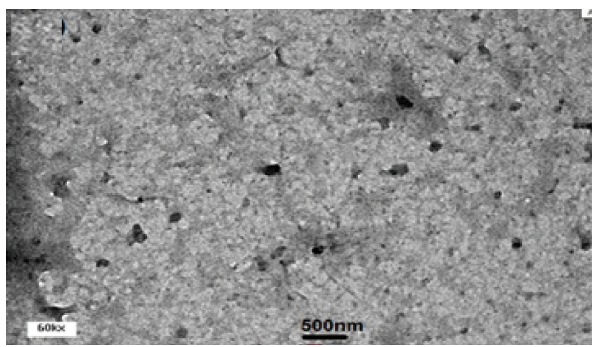

(f)

FIGURE 1: AFM micrographs of DsiRNA-CS nanoparticles (prepared from 0.3\% w/v CS) of 2-dimensional (a) and 3-dimensional (b). TEM micrographs of DsiRNA-CS nanoparticles prepared from $0.1 \%$ (c), $0.2 \%$ (d), $0.3 \%$ (e), and $0.4 \%$ (f) w/v CS at different magnifications ( $9900 \mathrm{x}$, $60 \mathrm{kx}, 26500 \mathrm{x})$.

within the nanoparticles' matrices and strong binding of DsiRNA that was located on the nanoparticles' surfaces. However, DsiRNA is expected to be gradually released from the nanoparticles following degradation of the polymeric matrices [34, 35].

In heparin displacement assay experiment, heparin was used to displace DsiRNA from CS nanoparticles prepared with different CS concentrations $(0.1 \%, 0.2 \%, 0.3 \%$, and $0.4 \% \mathrm{w} / \mathrm{v}$ ), as shown in Figure $2(\mathrm{c})$. The results suggested that DsiRNA was reversibly bound to CS nanoparticles. Despite that, a higher concentration of heparin $(10 \mathrm{mg} / \mathrm{mL})$ was needed to displace entrapped DsiRNA from CS nanoparticles suggesting stronger binding between entrapped DsiRNA (those located on/near to the particles' surfaces) and CS nanoparticles. Meanwhile, the release of entrapped DsiRNA within the matrices might occur when the polymer's matrices start to hydrate and swell. Moreover, a similar migration distance of the bands to the control (naked DsiRNA) further indicated that CS nanoparticles were able to load DsiRNA without altering its molecular structure.
3.2.1. Stability of DsiRNA-CS Nanoparticles. The ability of a carrier to protect its payload from nuclease degradation is an important property for efficient gene delivery. Similar to siRNA, DsiRNA must also be protected from nuclease digestion for maximal activity in the cells. To address this, a serum protection test was carried out for CS nanoparticles in $10 \%$ FBS. Naked DsiRNA started to degrade as early as 0 min due to degradation during mixing and freezing steps as shown in Figure 3(a). Naked DsiRNA was almost totally degraded after $48 \mathrm{~h}$ incubation in FBS. On the other hand, CS nanoparticles were able to completely protect the entrapped DsiRNA from nuclease degradation for up to $48 \mathrm{~h}$ incubation as indicated by DsiRNA bands with similar brightness and migration distance as those before the treatment $(0 \mathrm{~min})$. The bands were quantitatively analyzed using ImageJ software as shown in Figure 3(b). The relative density of DsiRNA bands released from CS nanoparticles was higher than naked DsiRNA. Therefore, CS nanoparticles were effectively protecting DsiRNA from the enzymatic activity of serum components. 


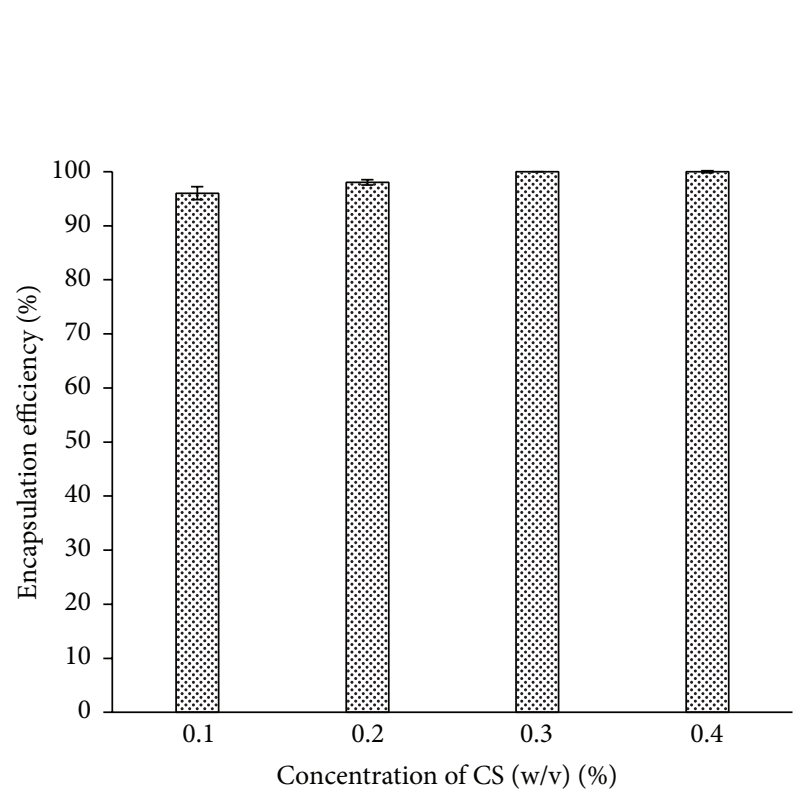

(a)

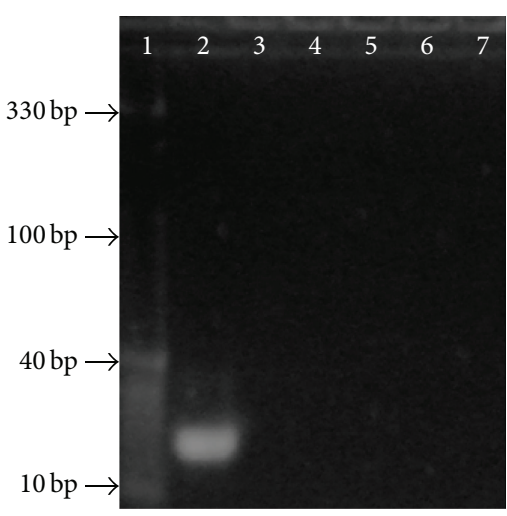

(1) DNA ladder (10 bp)

(2) Naked DsiRNA

(3) Unloaded CS nanoparticles

(4) $0.1 \% \mathrm{w} / \mathrm{v}$ CS

(5) $0.2 \% \mathrm{w} / \mathrm{v}$ CS DsiRNA-CS

(6) $0.3 \% \mathrm{w} / \mathrm{v}$ CS nanoparticles

(7) $0.4 \% \mathrm{w} / \mathrm{v}$ CS

(b)

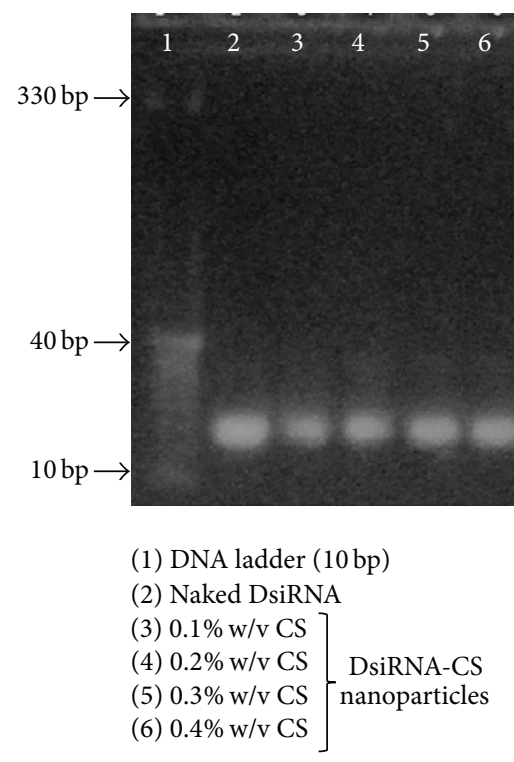

(c)

FIGURE 2: Encapsulation efficiency (a) of DsiRNA-CS nanoparticles prepared from different CS concentrations $(0.1 \%$ to $0.4 \% \mathrm{w} / \mathrm{v}$ CS), $n=3$. Binding efficiency (b) and heparin displacement assay (c) of DsiRNA-CS nanoparticles as determined by $4 \%$ w/v agarose gel electrophoresis.

Currently, to our knowledge, there is no information regarding the stability and integrity of DsiRNA-carriers in human serum. Knowledge about the effects of human serum on the stability of DsiRNA-carriers may help in the development of new, more promising DsiRNA-carriers. This experiment was conducted using DsiRNA-CS nanoparticles. Naked DsiRNA started to degrade at as early as 0 min incubation as shown in Figure 4. The smeared or diffused bands were observed after 30 min incubation of naked DsiRNA in human serum and the same observation was obtained after $48 \mathrm{~h}$ incubation. Moreover, migration distance of trailing bands after $30 \mathrm{~min}$ incubation increases in comparison to $0 \mathrm{~min}$ and control bands indicate degradation of DsiRNA by serum nucleases. The smeared naked DsiRNA is probably due to the presence of autofluorescent proteins or interactions with SYBR Green dye [36]. This finding is in accordance with the previous reports about naked siRNA in human serum $[36,37]$. CS nanoparticles effectively protected DsiRNA from the activity of serum nucleases for up to $48 \mathrm{~h}$ of incubation as indicated by the appearance of bands of similar brightness and migration distance to the DsiRNA band before the treatment $(0 \mathrm{~min})$. However, interpretation and quantification of 


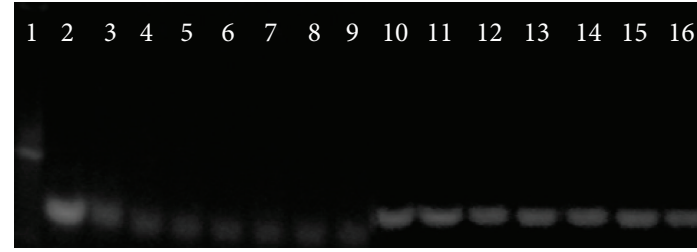

(1) DNA ladder (10 bp)

(2) Free DsiRNA (control)

Naked DsiRNA:

$\begin{array}{ll}\text { (3) } 0 \mathrm{~min} & \text { (10) } 0 \mathrm{~min} \\ \text { (4) } 30 \mathrm{~min} & (11) 30 \mathrm{~min} \\ \text { (5) } 2 \mathrm{~h} & (12) 2 \mathrm{~h} \\ \text { (6) } 4 \mathrm{~h} & (13) 4 \mathrm{~h} \\ \text { (7) } 7 \mathrm{~h} & (14) 7 \mathrm{~h} \\ \text { (8) } 24 \mathrm{~h} & (15) 24 \mathrm{~h} \\ \text { (9) } 48 \mathrm{~h} & \text { (16) } 48 \mathrm{~h}\end{array}$

(a)

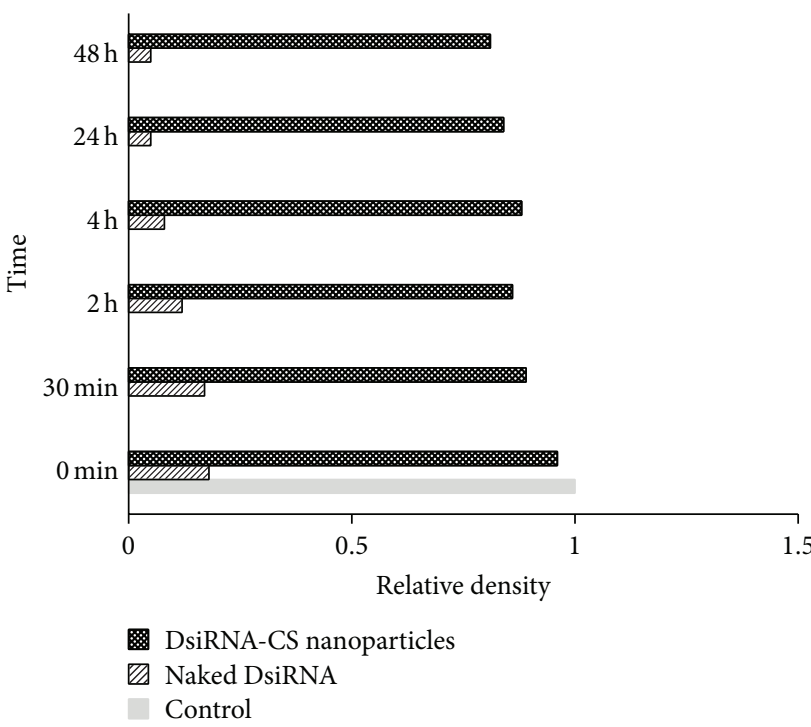

(b)

FIGURE 3: Electrophoretic mobility (a) of naked DsiRNA and DsiRNA-CS nanoparticles, following incubation in RPMI medium containing $10 \%$ FBS for $48 \mathrm{~h}$. Relative density (b) of gel electrophoresis bands of serum protection assay (FBS), by imageJ software.

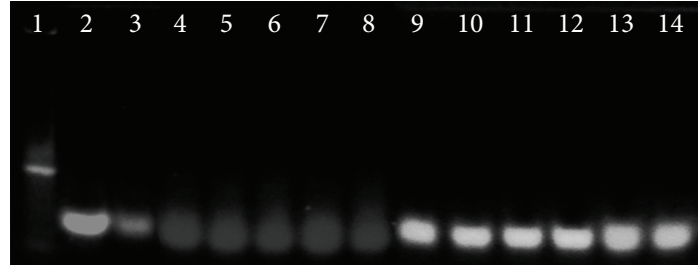

(1) DNA ladder (10 bp)

(2) Free DsiRNA (control)

Naked DsiRNA:

DsiRNA-CS nanoparticles:

(3) $0 \mathrm{~min}$

(4) $30 \mathrm{~min}$

(5) $4 \mathrm{~h}$

(6) $7 \mathrm{~h}$

(7) $24 \mathrm{~h}$

(8) $48 \mathrm{~h}$

(9) $0 \mathrm{~min}$

(10) $30 \mathrm{~min}$

(11) $4 \mathrm{~h}$

(12) $7 \mathrm{~h}$

(13) $24 \mathrm{~h}$

(14) $48 \mathrm{~h}$

FIGURE 4: Electrophoretic mobility of naked DsiRNA and DsiRNACS nanoparticles following incubation in human serum for $48 \mathrm{~h}$.

the relative density of the DsiRNA bands in the presence of human serum could not be obtained because the diffused bands were difficult to quantify.

3.2.2. Storage Stability. The study was performed in deionized distilled water or PBS ( $\mathrm{pH} 7.4$ ) for 15 days. The storage stability of DsiRNA-CS nanoparticles (CS concentration of $0.3 \% \mathrm{w} / \mathrm{v}$ ) in deionized distilled water at $4^{\circ} \mathrm{C}$ and $25^{\circ} \mathrm{C}$ is shown in Figures 5(a) and 5(b), respectively. The results demonstrated that DsiRNA-CS nanoparticles were stable in deionized distilled water, as particle size remained unchanged at both temperatures. Similar findings were obtained when DsiRNACS nanoparticles were suspended in PBS and stored at $4^{\circ} \mathrm{C}$ and $25^{\circ} \mathrm{C}$, as shown in Figures 5(c) and 5(d), respectively. The cross-linking effect of TPP in the formation of DsiRNACS nanoparticles confers its action as a stabilizer, producing structures, which are less prone to aggregations [38].

3.2.3. In Vitro Release. The in vitro release study of DsiRNA from CS nanoparticles (CS concentration of $0.3 \% \mathrm{w} / \mathrm{v}$ ) was carried out using PBS at $\mathrm{pH} 7.4$ for 15 days (Figure 6). A rapid release in the first four days was also observed for these nanoparticles, resulting in an $18 \%$ cumulative release of DsiRNA. The rapid release might be attributed by the release of loosely bound DsiRNA located near or on the particles' surfaces. From day 5 until the last day of the experiment, DsiRNA was released from CS nanoparticles at a constant rate with $40 \%$ total cumulative release of DsiRNA. The release at this stage might be due to erosion or a combination of erosion and diffusion processes of the nanoparticles' matrices as previously reported [39].

3.2.4. Cytotoxicity. The cytotoxic effect of DsiRNA-CS nanoparticles was investigated in V79, DLD-1, and HUVECs cell lines by an alamarBlue cell viability assay. In V79 cells, only a 5-11\% loss of cell viability was observed for DsiRNACS nanoparticles as shown in Figure 7(a). The cytotoxicity of DsiRNA-CS nanoparticles was not significantly different between 24 and $48 \mathrm{~h}$ incubations. Generally, cell viability decreased as CS concentration used to prepare the nanoparticles increased from $0.1 \%$ to $0.4 \% \mathrm{w} / \mathrm{v}$.

In the DLD-1 cell line, DsiRNA-CS nanoparticles caused a cytotoxic effect after 24 and $48 \mathrm{~h}$ incubation as shown in Figure $7(\mathrm{~b})$. The cell viability decreased significantly as the CS concentration used to prepare CS nanoparticles increased from $0.1 \%$ to $0.4 \% \mathrm{w} / \mathrm{v}$ due to a higher density of positive charges in the CS. This condition induced unspecific 


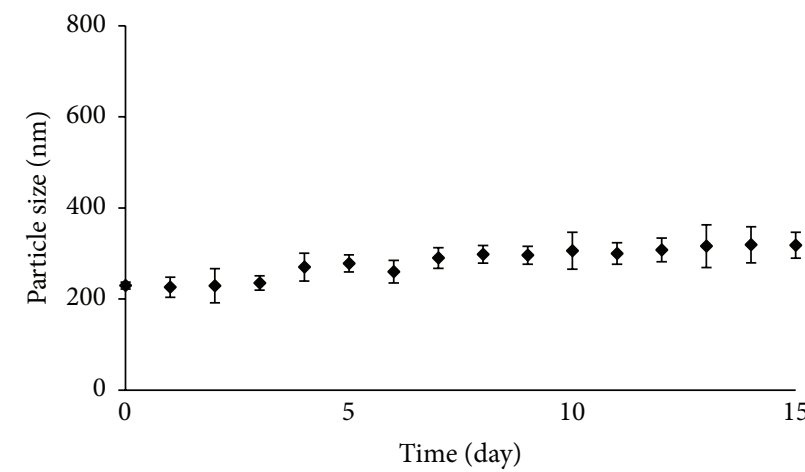

(a)

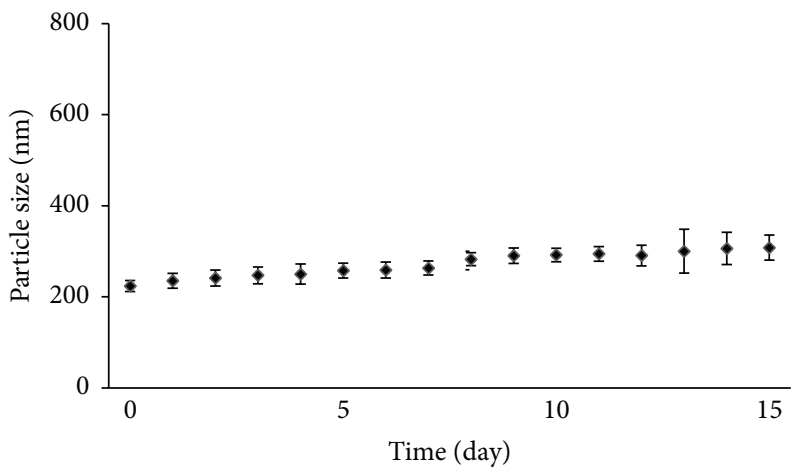

(c)

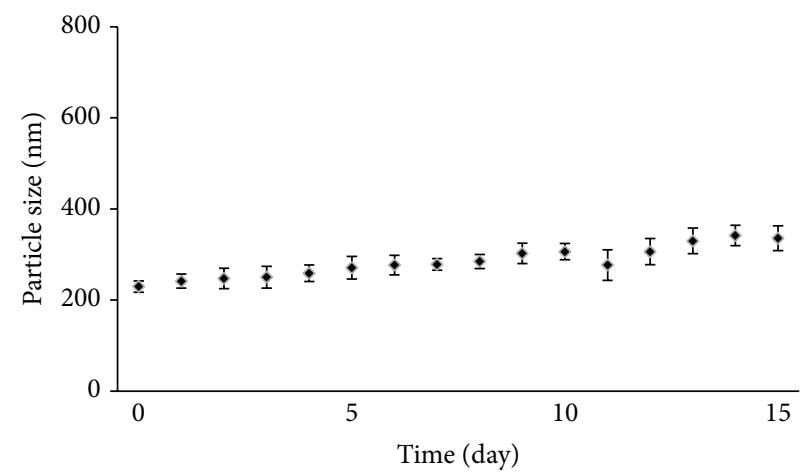

(b)

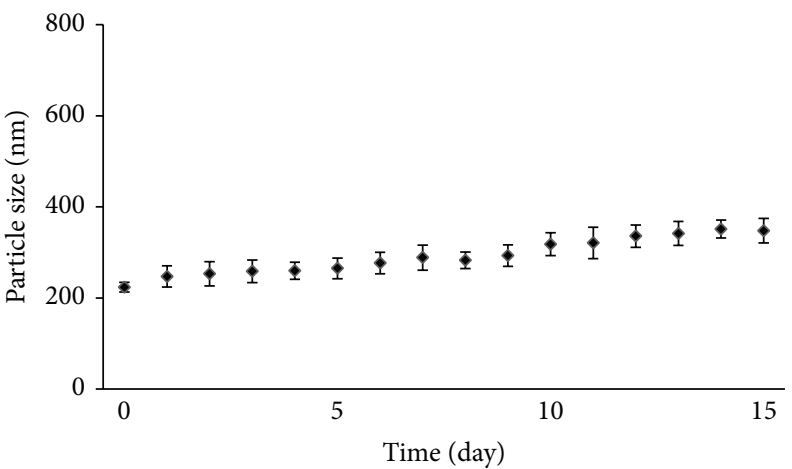

(d)

Figure 5: Storage stability of DsiRNA-CS nanoparticles: in deionized distilled water at $4^{\circ} \mathrm{C}$ (a) and $25^{\circ} \mathrm{C}$ (b) and in $\mathrm{PBS}$ at $4^{\circ} \mathrm{C}(\mathrm{c})$ and $25^{\circ} \mathrm{C}$ (d), for 15 days, $n=3$.

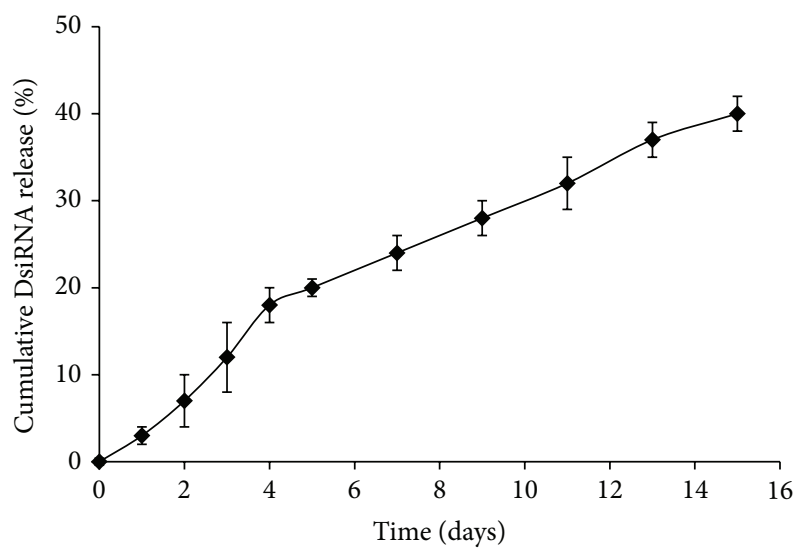

FIGURE 6: The release profile of DsiRNA-CS nanoparticles at $\mathrm{pH} 7.4$ for 15 days, $n=3$.

interactions with the cell membranes, destroying the integrity of the cell membrane $[40,41]$. The cytotoxicity of DsiRNACS nanoparticles in DLD-1 cells was further increased after $48 \mathrm{~h}$ incubation. The loss of cell viability of DLD-1 cells was expected to be greater than that of the normal cells because CS has the ability to inhibit the growth of human cancer cells through an antiangiogenic mechanism [42].

HUVECs are isolated from the vein of the umbilical cord and are commonly used for physiological and pharmacological investigations involving macromolecule transport, blood coagulation, angiogenesis, and fibrinolysis. In addition, HUVECs are also available which are prescreened for VEGF response. VEGF is an important signaling protein involved in both vasculogenesis and angiogenesis. In vitro, VEGF has been shown to stimulate endothelial cell mitogenesis, cell migration, sprouting, and microvascular permeability. In HUVECs, a $7-18 \%$ loss of cell viability was observed when the cells were treated with DsiRNA-CS nanoparticles (Figure 7(c)). Different CS nanoparticles made from various CS concentrations did not significantly affect the cell viability after 24 and $48 \mathrm{~h}$ incubation even though a deceasing trend in cell viability could be seen. A significant decrease in cell viability was observed after $48 \mathrm{~h}$ incubation compared to $24 \mathrm{~h}$ incubation, suggesting the progressiveness of the cytotoxicity effect over time. This could be due to the silencing activity of DsiRNA against the targeted VEGF gene resulting in cell death. Therefore, it can be concluded that CS nanoparticles have the potential ability to deliver DsiRNA into the target site and could be applied in cancer therapy by inhibiting angiogenesis, which may control tumor growth and metastasis [43]. However, further investigation is necessary to address this effect.

For LIVE/DEAD cell viability assay, the results showed that untreated cells did not produce any loss of cell viability (Figure $8(\mathrm{a})(\mathrm{A})$ and $(\mathrm{D})$ ), while some loss was observed in the cells treated with naked DsiRNA (Figure $8(\mathrm{a})(\mathrm{B})$ and 


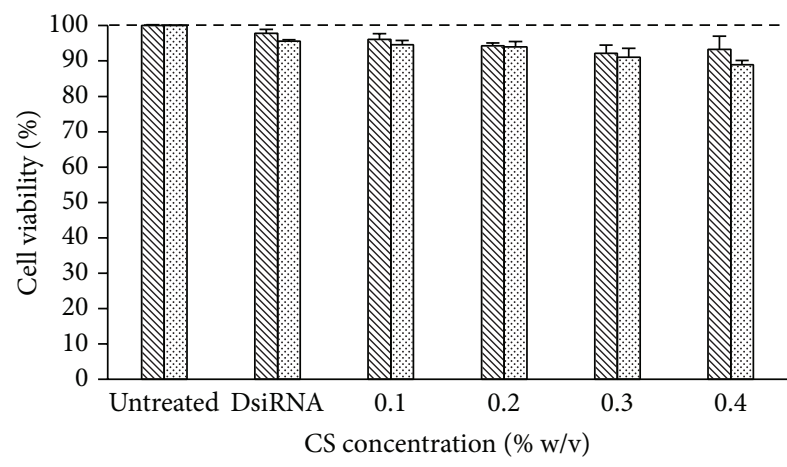

$\mathbb{N} 24 h$
$78 h$

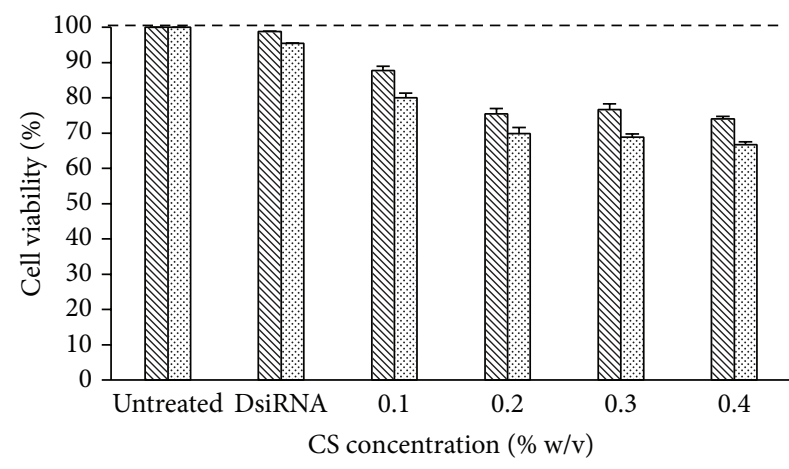

$\mathbb{\mathbb { N }} 24 \mathrm{~h}$

图 $48 \mathrm{~h}$

(a)

(b)

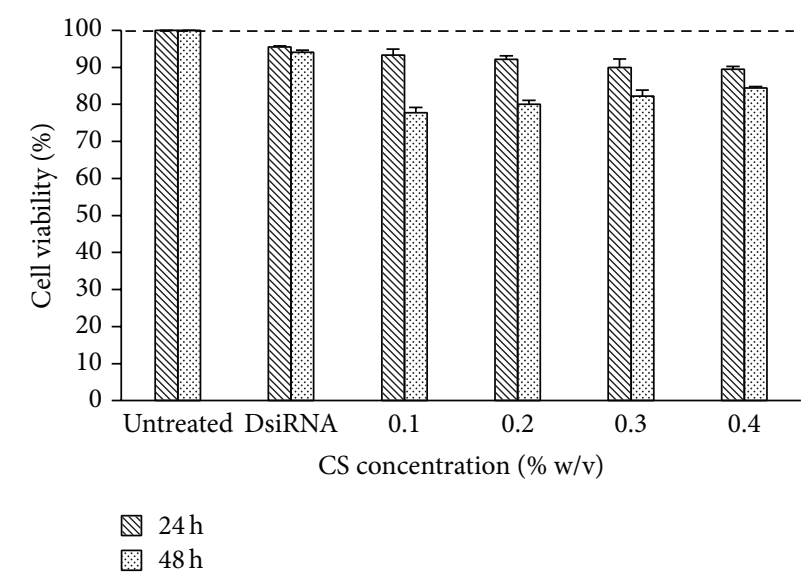

(c)

Figure 7: Cytotoxicity effects of DsiRNA-CS nanoparticles after 24 and $48 \mathrm{~h}$ incubation in V79 (a), DLD-1 (b), and HUVECs (c) cell lines, $n=3$.

(E)). These results are in accordance with the results from the cytotoxicity assays using alamarBlue that also showed some cell death (red color) after $24 \mathrm{~h}$ of the cells treated with DsiRNA-CS nanoparticles (Figure 8(a)(C)). Furthermore, an increase in cell death was observed after $48 \mathrm{~h}$ incubation as indicated by the presence of red color (dead cells), as shown in Figure 8(a)(F).

3.2.5. DsiRNA Internalization/Cellular Uptake. After incubation of DLD-1 cells with 6-FAM-DsiRNA entrapped within CS nanoparticles for $6 \mathrm{~h}$, fluorescence could be detected within the cells. The fluorescence was mainly distributed in the cytoplasm, which is in agreement with previous observations for siRNA cellular uptake and an earlier report (Figures 8(b)(D)-(F)) [44]. However, fluorescence from the naked 6FAM-DsiRNA could not be detected (Figure 8(b)(A)-(C)). Therefore, the results of this study suggested that DsiRNA entrapped within CS nanoparticles could efficiently deliver DsiRNA into cells, particularly the cytoplasm.

3.2.6. In Vitro Gene Silencing. In order to investigate the silencing activity of VEGF mRNA, RT-PCR was used to determine the VEGF mRNA level in DLD-1 cells. In this experiment, samples consisted of a negative control (Lipofectamine and scrambled DsiRNA), positive control (Lipofectamine and VEGF DsiRNA), and DsiRNA-CS nanoparticles. The concentration of DsiRNA ( $80 \mathrm{pmol}$ ) was kept constant in all formulations. The quality of housekeeping (Figure 9(a)) and VEGF mRNA (Figure 9(b)) was also assessed using $1 \% \mathrm{w} / \mathrm{v}$ agarose gel electrophoresis. A quantitative analysis of VEGF mRNA level was performed using imageJ software (Figure 9(c)). The results showed that the negative control did not show any silencing effect in the target gene. The highest gene silencing activity was observed in the positive control. However, DsiRNA-CS nanoparticles showed a significant decrease in VEGF mRNA level in comparison to the negative control, and this level was comparable to the positive control. The high gene silencing activity of DsiRNACS nanoparticles compared to a positive control was expected because, as previously discussed, these particles provided maximum stability in FBS and human serum. Interestingly, a very low concentration of DsiRNA ( $80 \mathrm{pmol})$ was used in this study which is lower than the concentration of siRNA (100-250 nmol) commonly used to silence target genes. Thus, DsiRNA was found to be more potent than siRNA in silencing the VEGF gene. 


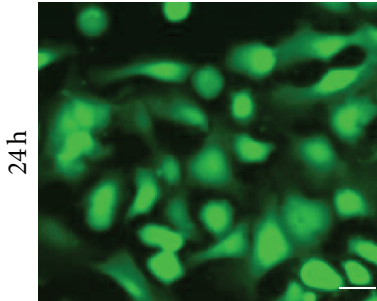

(A)

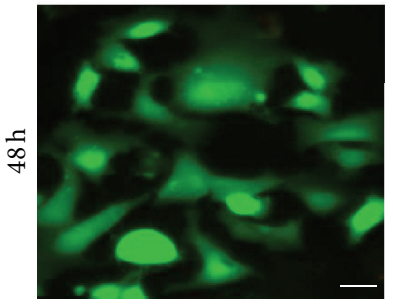

(D)

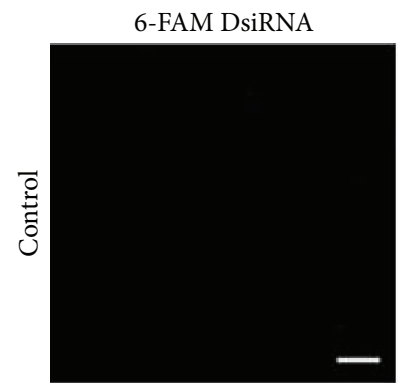

(A)

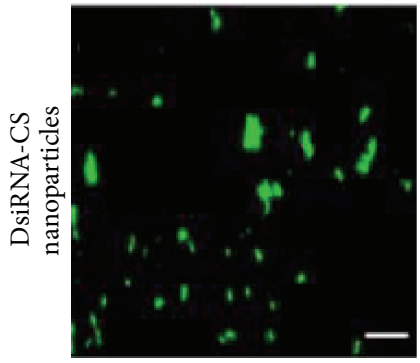

(D)

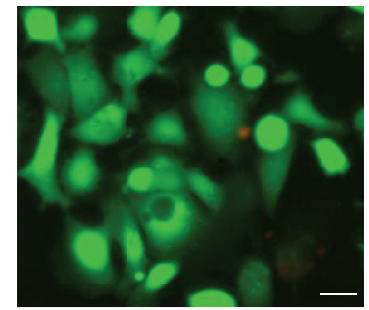

(B)

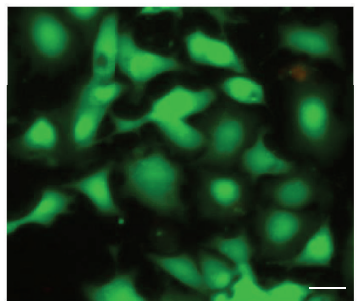

(E)

(a)

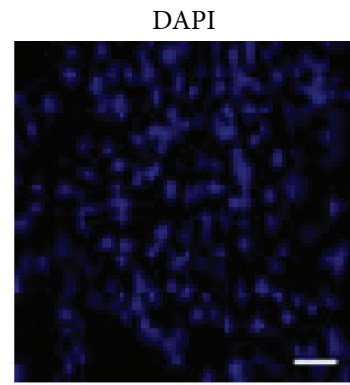

(B)

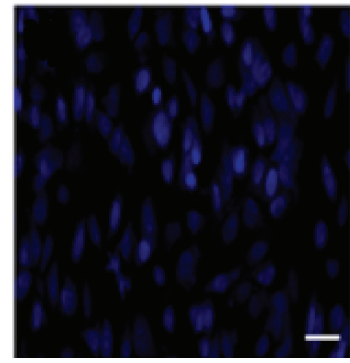

(E)

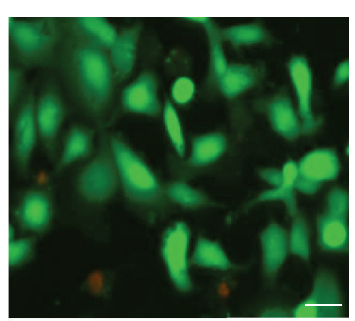

(C)

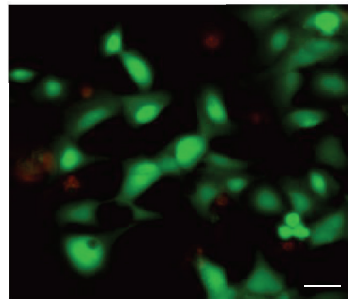

(F)

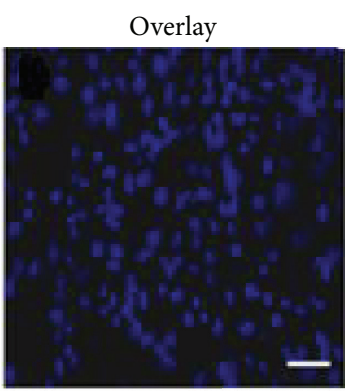

(C)

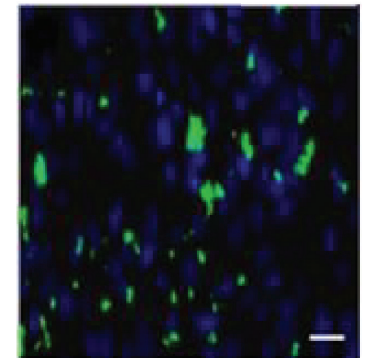

(F)

(b)

FIGURE 8: (a) Live/dead cell viability assay of DsiRNA-CS nanoparticles in DLD-1 cells after $24 \mathrm{~h}$ and $48 \mathrm{~h}$ incubation. Untreated cells (A, D), naked DsiRNA (B, E), and DsiRNA-CS nanoparticles (C, F) after $24 \mathrm{~h}$ and $48 \mathrm{~h}$ incubation, respectively (green and red colors represent viable and dead cells, resp.). (b) Internalization and localization of 6-FAM-labeled DsiRNA-CS nanoparticles in DLD-1 cells after $6 \mathrm{~h}$ incubation. Scale bar represents $10 \mu \mathrm{m}$.

3.2.7. Morphology of MCLs. The morphology of the collagen layer and 6 days of growth of MCLs was examined using SEM (Figures 9(d), 9(e), and 9(f)). The results showed that MCLs were tightly attached to the collagen layer (basement membrane). Cells were difficult to view on the surface due to the secretion of a large amount of ECM, as reported previously [45]. The collagen layer can be observed in Figure 9(d). MCLs that attached to the collagen layer as a basement membrane can be observed in Figures 9(e) and 9(f).
3.2.8. VEGF Gene Silencing within MCLs. Across a wide range of human tumors and/or cell lines, expression of VEGF leads to the development and maintenance of a vascular network that promotes tumor growth. Moreover, evidence obtained from tumor studies indicates the involvement of both VEGF gene expression and VEGF production in tumor growth. Thus, the MCLs thickness is correlated with VEGF expressions reported elsewhere [29]. The thickness of MCLs without treatment was calculated using software (Analysis 


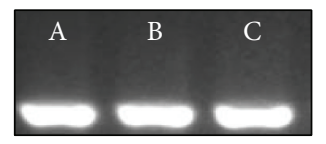
(A) Negative control
(B) Positive control
(C) DsiRNA-CS nanoparticles

(a)

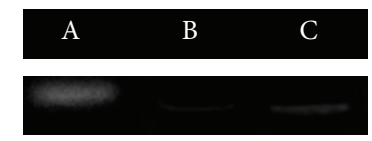

(A) Negative control

(B) Positive control

(C) DsiRNA-CS

nanoparticles

(b)

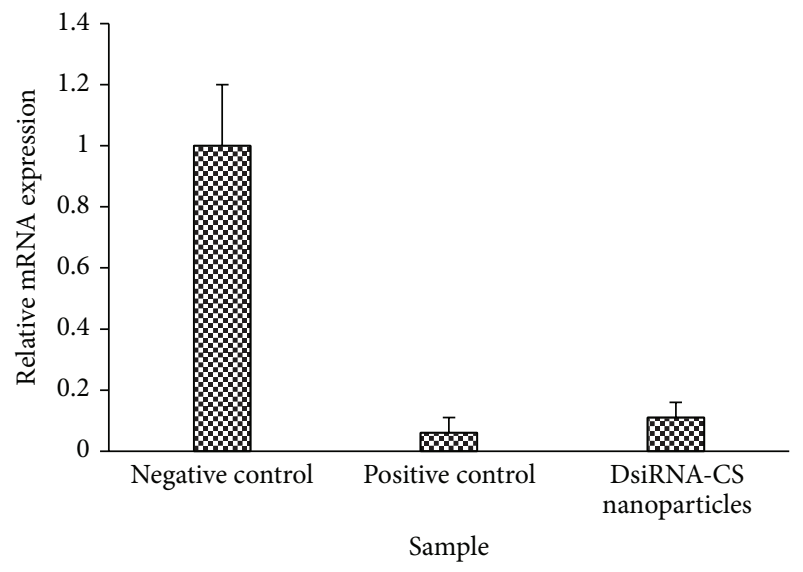

(c)

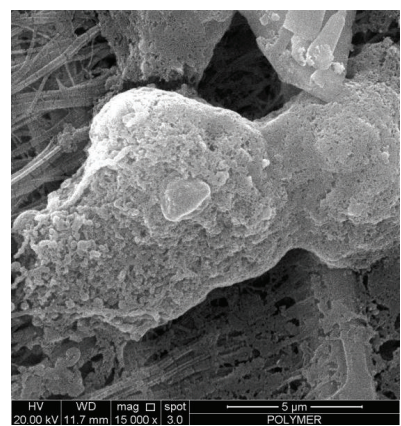

(f)

Figure 9: Analysis of VEGF mRNA suppression using RT-PCR. Images of agarose gel electrophoresis $1 \%$ show the bands of GAPDH (housekeeping gene) (a) and VEGF (b). The graph represents relative mRNA expression in DLD-1 cells after treatment with different samples (c). SEM images of collagen layer (d) and MCLs at different magnifications (1000x (d), 15000x (e), and 20000x (f)).

LS Report) and an optical microscope. The thickness was calculated to be in the range of $200 \pm 20 \mu \mathrm{m}$. The expression of VEGF mRNA was determined within the MCLs after exposure to naked DsiRNA and DsiRNA-CS nanoparticles (20 and $80 \mathrm{pmol}$ ) targeting VEGF after 24 and $48 \mathrm{~h}$ incubations. This concentration was used because the risk of off-target effects can be reduced if the DsiRNA concentration is below $100 \mathrm{pmol}$ when the effective transfection reagent and protocol are applied [7]. No significant changes in VEGF mRNA levels were observed in MCLs when treated with naked DsiRNA in comparison to the untreated control group (Figures 10(a)(A) and (B)), indicating the absence of a gene silencing effect. On the other hand, the VEGF mRNA level decreased significantly compared to the untreated control group when MCLs were exposed to DsiRNA-CS nanoparticles (20 and 80 pmol) after 24 and $48 \mathrm{~h}$ incubations (Figures $10(\mathrm{a})(\mathrm{C})-(\mathrm{F})$ ). The results also showed that DsiRNA-CS nanoparticles caused a higher loss of VEGF mRNA at $80 \mathrm{pmol}$ (Figures 10(a)(E) and (F)) in comparison to $20 \mathrm{pmol}$ as shown in (Figures $10(\mathrm{a})(\mathrm{C})$ and (D)). Moreover, a higher reduction of VEGF mRNA was observed at both concentrations after $48 \mathrm{~h}$ incubation as shown in Figures 10(a)(D) and (F). Thus, the gene silencing effect in MCLs was concentration- and time-dependent, showing more suppression at higher concentrations and longer incubation periods. In addition, DsiRNA could be used to silence target genes associated with solid tumors at a 2.5-fold lesser concentration than siRNA, and this could help with avoiding off-target effects.

3.2.9. ELISA Analysis for VEGF Protein in MCLs. The VEGF levels in MCLs were determined by ELISA after exposure to naked DsiRNA, CS nanoparticles (unloaded), and DsiRNACS nanoparticles for 24 and $48 \mathrm{~h}$. A DsiRNA concentration of $80 \mathrm{pmol}$ was used in all formulations. The results showed that naked DsiRNA did not exert any significant reduction in the VEGF level in MCLs when compared to untreated cells (Figure 10(b)). This finding is in accordance with the previous report on siRNA [29]. Moreover, Figure 10(b) shows a significant reduction in VEGF levels when MCLs were treated with DsiRNA-CS nanoparticles in comparison to untreated cells. The significant decrease in VEGF level was also observed after $48 \mathrm{~h}$ exposure of DsiRNA-CS nanoparticles. This significant decrease in VEGF level might be due to maximum protection of DsiRNA provided by the CS nanoparticles in FBS and human serum as discussed above.

3.2.10. DsiRNA Distribution within MCLs. DsiRNA distribution in MCLs was evaluated upon exposure of 6-FAMlabeled naked DsiRNA entrapped into CS nanoparticles ( $80 \mathrm{pmol}$ ) for 24 and $48 \mathrm{~h}$. The naked DsiRNA (control) only 


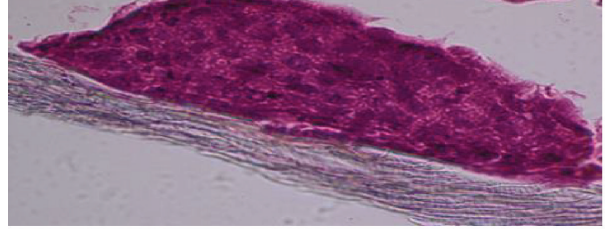

(A)

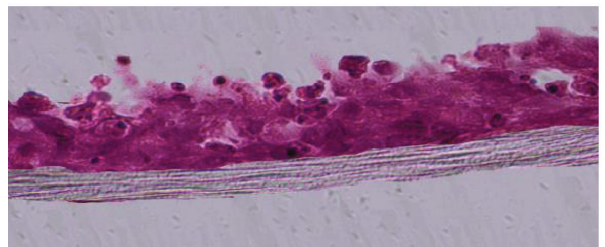

(C)

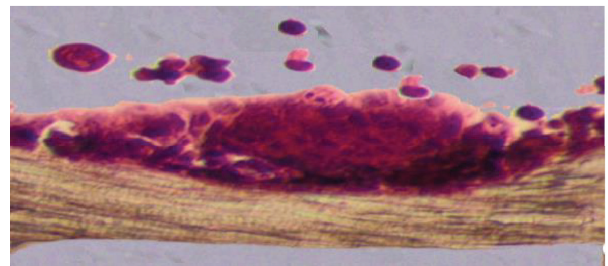

(E)

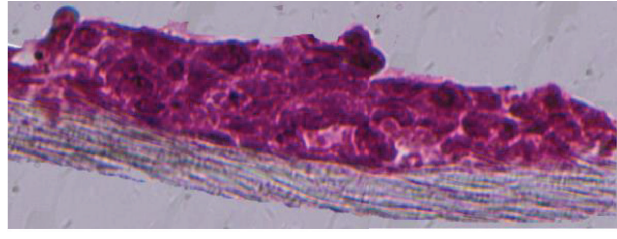

(B)

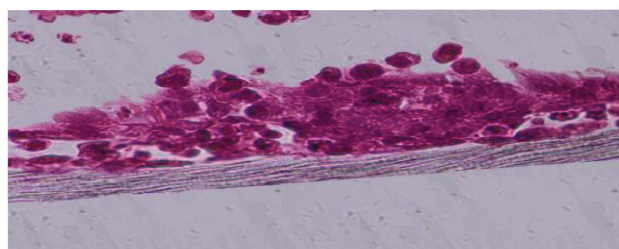

(D)

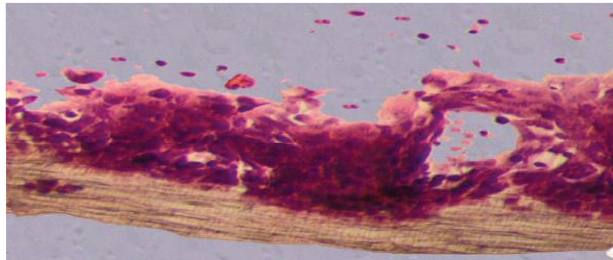

$(\mathrm{F})$

(a)

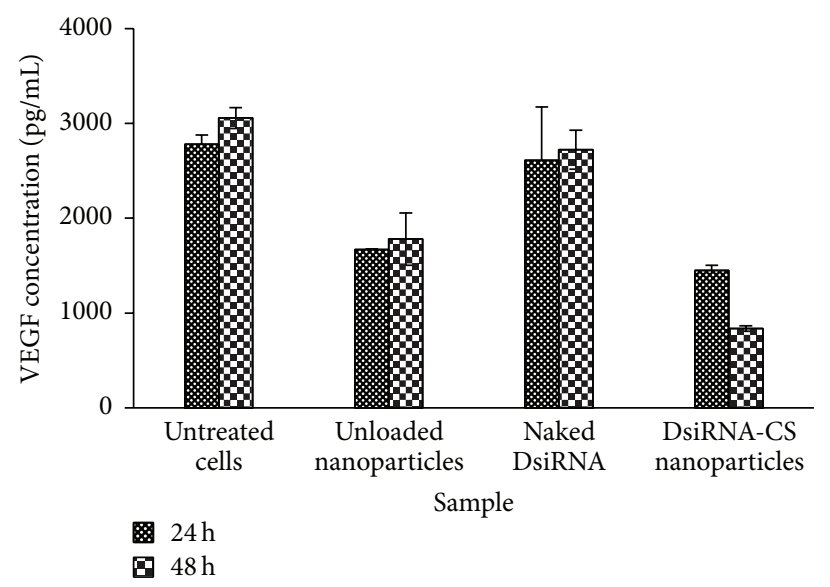

(b)

Figure 10: (a) VEGF mRNA expression in MCLs of DLD-1 cells of untreated MCLs (A), MCLs exposed to naked DsiRNA (B), DsiRNA-CS nanoparticles at $20 \mathrm{pmol}(\mathrm{C}$ and $\mathrm{D})$, and $80 \mathrm{pmol}(\mathrm{E}$ and $\mathrm{F}$ ) for 24 and $48 \mathrm{~h}$ incubations, respectively. (b) The level of VEGF protein in MCLs after exposure to DsiRNA-CS nanoparticles for 24 and $48 \mathrm{~h}$.

showed some fluorescence on the surface of MCLs with no penetration observed up to $48 \mathrm{~h}$ incubation (Figures 11(a) and 11(b)). For DsiRNA-CS nanoparticles, distribution was limited to the middle layer of MCLs after $24 \mathrm{~h}$ incubation (Figures 11(c) and 11(e)). However, after $48 \mathrm{~h}$ incubation complete and uniform penetration of DsiRNA was observed which could be detected by fluorescence throughout the MCLs (Figures 11(d) and 11(f)). Cell detachment from MCLs was also observed after $48 \mathrm{~h}$, indicating that the silencing effect of the target gene had subsequently contributed to the antitumor effect. This effect is in accordance with the previous findings that showed a significant reduction in VEGF levels caused by DsiRNA-CS nanoparticles and the effect was more pronounced after $48 \mathrm{~h}$. Fluorescence signals detected within MCLs demonstrated the ability of CS nanoparticles to deliver DsiRNA into cells and induce the RNAi effect as reported elsewhere [29].

\section{Conclusions}

DsiRNA-CS nanoparticles that had a small particle size, positive surface charge, regular morphology, high encapsulation efficiency, and exhibited sustained release of DsiRNA were successfully prepared by the ionic gelation method. Moreover, these nanoparticles provided maximal protection 
$24 \mathrm{~h}$

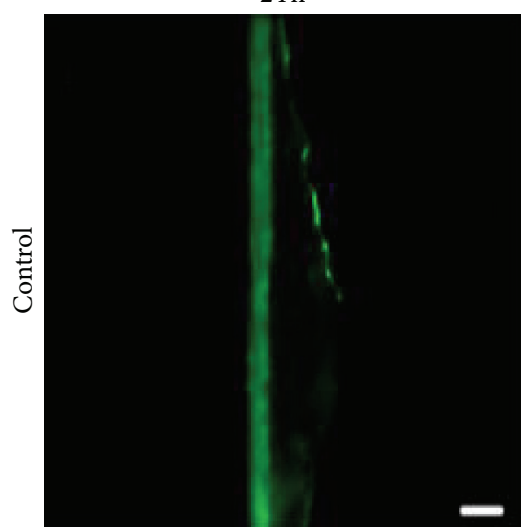

(a)

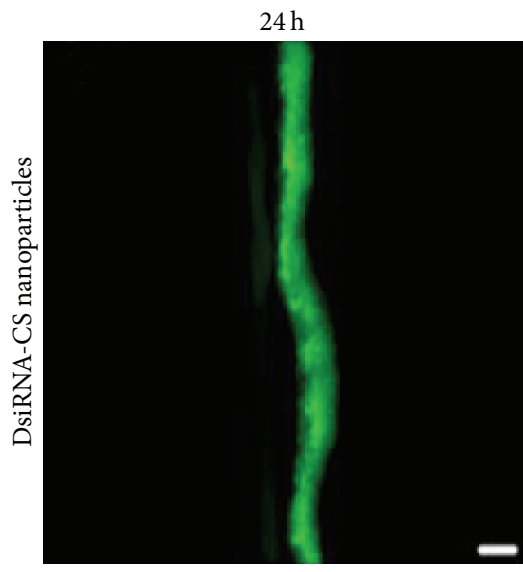

(c)

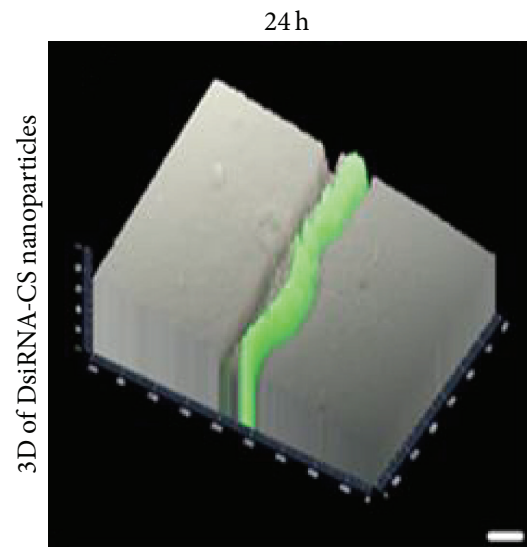

(e)

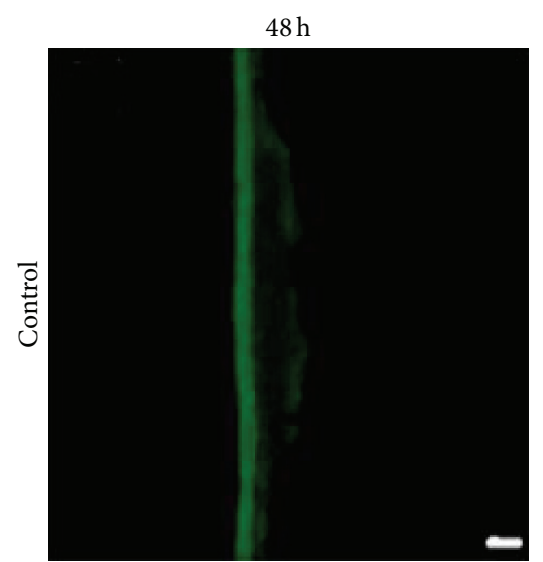

(b)

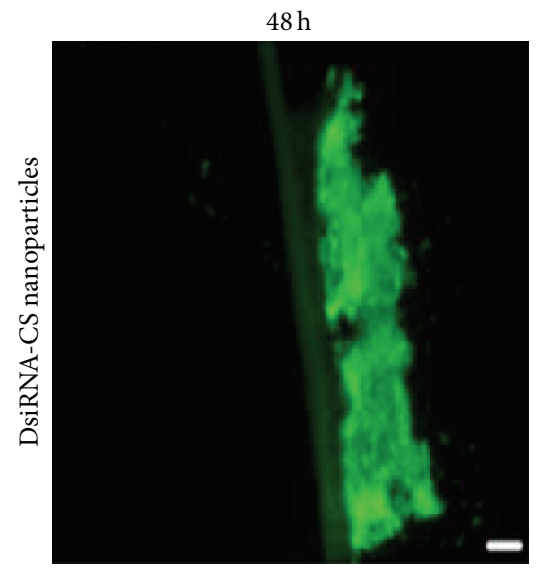

(d)

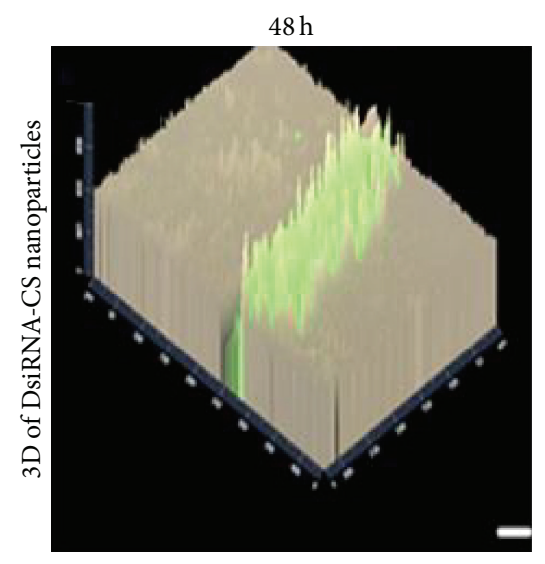

(f)

Figure 11: DsiRNA distribution in MCLs after 24 and $48 \mathrm{~h}$ incubation with naked 6-FAM DsiRNA (control) and 6-FAM DsiRNA-CS nanoparticles. Scale bar represents $50 \mu \mathrm{m}$.

of DsiRNA in $10 \%$ FBS and human serum for up to $48 \mathrm{~h}$ incubation. Cytotoxic effects were determined to be dependent on the concentration of CS in the case of V79 and DLD-1 cells and otherwise in the case of HUVECs. Moreover, DsiRNACS nanoparticles were successfully internalized into DLD1 cells. RT-PCR studies revealed that DsiRNA entrapped within CS nanoparticles could highly downregulate VEGF
mRNA levels in DLD-1 cells. The solid tumor model (MCLs) was successfully established in vitro. MCLs possessed a compact morphology. The gene silencing effect of MCLs was concentration- and time-dependent, showing greater suppression at $80 \mathrm{pmol}$ and for $48 \mathrm{~h}$ incubation. The findings are very promising because the highest DsiRNA concentration of $80 \mathrm{pmol}$ used in this study could effectively result in a gene 
silencing effect. This concentration is much lower than the concentration needed for siRNA (200 pmol) reported previously [29]. Thus, DsiRNA was more effective for silencing the target gene in solid tumors at a concentration 2.5-fold less than siRNA, and this reduction could prevent off-target effects. Moreover, CS has great prospective applications for DsiRNA delivery. Thus, DsiRNA-CS nanoparticles could be used in future in vivo studies.

\section{Competing Interests}

The authors report no competing interests in this work.

\section{Acknowledgments}

The authors gratefully acknowledge all the members of Centre for Drug Delivery Research Group for their technical support and advice and the Ministry of Education, Malaysia, for financially supporting the project (ERGS/1/2011/SKK/UKM/ 02/11).

\section{References}

[1] S. M. Elbashir, J. Harborth, W. Lendeckel, A. Yalcin, K. Weber, and T. Tuschl, "Duplexes of 21-nucleotide RNAs mediate RNA interference in cultured mammalian cells," Nature, vol. 411, no. 6836, pp. 494-498, 2001.

[2] R. K. M. Leung and P. A. Whittaker, "RNA interference: from gene silencing to gene-specific therapeutics," Pharmacology and Therapeutics, vol. 107, no. 2, pp. 222-239, 2005.

[3] J. S. Kang, Y. N. Yum, E. Han et al., "Evaluation of potential biomarkers for thioacetamide-induced hepatotoxicity using siRNA," Biomolecules and Therapeutics, vol. 16, no. 3, pp. 197202, 2008.

[4] T. C. Karagiannis and A. El-Osta, "RNA interference and potential therapeutic applications of short interfering RNAs," Cancer Gene Therapy, vol. 12, no. 10, pp. 787-795, 2005.

[5] J. C. Cheng, T. B. Moore, and K. M. Sakamoto, "RNA interference and human disease," Molecular Genetics and Metabolism, vol. 80, no. 1-2, pp. 121-128, 2003.

[6] S. D. Rose, D.-H. Kim, M. Amarzguioui et al., "Functional polarity is introduced by Dicer processing of short substrate RNAs," Nucleic Acids Research, vol. 33, no. 13, pp. 4140-4156, 2005.

[7] D.-H. Kim, M. A. Behlke, S. D. Rose, M.-S. Chang, S. Choi, and J. J. Rossi, "Synthetic dsRNA Dicer substrates enhance RNAi potency and efficacy," Nature Biotechnology, vol. 23, no. 2, pp. 222-226, 2005.

[8] D. Siolas, C. Lerner, J. Burchard et al., "Synthetic shRNAs as potent RNAi triggers," Nature Biotechnology, vol. 23, no. 2, pp. 227-231, 2005.

[9] R. C. C. Ryther, A. S. Flynt, J. A. Phillips, and J. G. Patton, "siRNA therapeutics: big potential from small RNAs," Gene Therapy, vol. 12, no. 1, pp. 5-11, 2005.

[10] J. M. Layzer, A. P. McCaffrey, A. K. Tanner, Z. Huang, M. A. Kay, and B. A. Sullenger, "In vivo activity of nuclease-resistant siRNAs," RNA, vol. 10, no. 5, pp. 766-771, 2004.

[11] S. Choung, Y. J. Kim, S. Kim, H.-O. Park, and Y.-C. Choi, "Chemical modification of siRNAs to improve serum stability without loss of efficacy," Biochemical and Biophysical Research Communications, vol. 342, no. 3, pp. 919-927, 2006.

[12] P. D. Cotter, C. Hill, and R. P. Ross, "Food microbiology: bacteriocins: developing innate immunity for food," Nature Reviews Microbiology, vol. 3, no. 10, pp. 777-788, 2005.

[13] M. Dash, F. Chiellini, R. M. Ottenbrite, and E. Chiellini, "Chitosan-a versatile semi-synthetic polymer in biomedical applications," Progress in Polymer Science, vol. 36, no. 8, pp. 9811014, 2011.

[14] M. Hamidi, A. Azadi, and P. Rafiei, "Hydrogel nanoparticles in drug delivery," Advanced Drug Delivery Reviews, vol. 60, no. 15, pp. 1638-1649, 2008.

[15] Z. Liu, Y. Jiao, Y. Wang, C. Zhou, and Z. Zhang, "Polysaccharides-based nanoparticles as drug delivery systems," Advanced Drug Delivery Reviews, vol. 60, no. 15, pp. 1650-1662, 2008.

[16] L. Illum, "Chitosan and its use as a pharmaceutical excipient," Pharmaceutical Research, vol. 15, no. 9, pp. 1326-1331, 1998.

[17] J. Malmo, K. M. Vårum, and S. P. Strand, "Effect of chitosan chain architecture on gene delivery: comparison of selfbranched and linear chitosans," Biomacromolecules, vol. 12, no. 3, pp. 721-729, 2011.

[18] S. P. Strand, M. M. Issa, B. E. Christensen, K. M. Vårum, and P. Artursson, "Tailoring of chitosans for gene delivery: novel self-branched glycosylated chitosan oligomers with improved functional properties," Biomacromolecules, vol. 9, no. 11, pp. 3268-3276, 2008.

[19] O. Germershaus, S. Mao, J. Sitterberg, U. Bakowsky, and T. Kissel, "Gene delivery using chitosan, trimethyl chitosan or polyethylenglycol-graft-trimethyl chitosan block copolymers: establishment of structure-activity relationships in vitro," Journal of Controlled Release, vol. 125, no. 2, pp. 145-154, 2008.

[20] P. Baldrick, "The safety of chitosan as a pharmaceutical excipient," Regulatory Toxicology and Pharmacology, vol. 56, no. 3, pp. 290-299, 2010.

[21] M. Izquierdo, "Short interfering RNAs as a tool for cancer gene therapy," Cancer Gene Therapy, vol. 12, no. 3, pp. 217-227, 2005.

[22] R. S. Kerbel, "Improving conventional or low dose metronomic chemotherapy with targeted antiangiogenic drugs," Cancer Research and Treatment, vol. 39, no. 4, pp. 150-159, 2007.

[23] F. Fan, J. S. Wey, M. F. McCarty et al., "Expression and function of vascular endothelial growth factor receptor-1 on human colorectal cancer cells," Oncogene, vol. 24, no. 16, pp. 2647-2653, 2005.

[24] D. J. Hicklin and L. M. Ellis, "Role of the vascular endothelial growth factor pathway in tumor growth and angiogenesis," Journal of Clinical Oncology, vol. 23, no. 5, pp. 1011-1027, 2005.

[25] M. Calvani, D. Trisciuoglio, C. Bergamaschi, R. H. Shoemaker, and G. Melillo, "Differential involvement of vascular endothelial growth factor in the survival of hypoxic colon cancer cells," Cancer Research, vol. 68, no. 1, pp. 285-291, 2008.

[26] B. Desoize, "Contribution of three-dimensional culture to cancer research," Critical Reviews in Oncology/Hematology, vol. 36, no. 2-3, pp. 59-60, 2000.

[27] K. O. Hicks, F. B. Pruijn, J. R. Sturman, W. A. Denny, and W. R. Wilson, "Multicellular resistance to tirapazamine is due to restricted extravascular transport: a pharmacokinetic/ pharmacodynamic study in HT29 multicellular layer cultures," Cancer Research, vol. 63, no. 18, pp. 5970-5977, 2003.

[28] P. Calvo, C. Remunán-López, J. L. Vila-Jato, and M. J. Alonso, "Novel hydrophilic chitosan-polyethylene oxide nanoparticles 
as protein carriers," Journal of Applied Polymer Science, vol. 63, no. 1, pp. 125-132, 1997.

[29] A. M. Al-Abd, S. H. Lee, S. H. Kim et al., "Penetration and efficacy of VEGF siRNA using polyelectrolyte complex micelles in a human solid tumor model in-vitro," Journal of Controlled Release, vol. 137, no. 2, pp. 130-135, 2009.

[30] T. Sonoda, H. Kobayashi, T. Kaku, T. Hirakawa, and H. Nakano, "Expression of angiogenesis factors in monolayer culture, multicellular spheroid and in vivo transplanted tumor by human ovarian cancer cell lines," Cancer Letters, vol. 196, no. 2, pp. 229237, 2003.

[31] S. A. Papadimitriou, D. S. Achilias, and D. N. Bikiaris, "Chitosan-g-PEG nanoparticles ionically crosslinked with poly(glutamic acid) and tripolyphosphate as protein delivery systems," International Journal of Pharmaceutics, vol. 430, no. 1-2, pp. 318-327, 2012.

[32] I. Hajdu, M. Bodnár, G. Filipcsei et al., "Nanoparticles prepared by self-assembly of chitosan and poly- $\gamma$-glutamic acid," Colloid and Polymer Science, vol. 286, no. 3, pp. 343-350, 2008.

[33] M. Abdul Ghafoor Raja, H. Katas, Z. Abd Hamid, and N. A. Razali, "Physicochemical properties and in vitro cytotoxicity studies of chitosan as a potential carrier for dicer-substrate siRNA," Journal of Nanomaterials, vol. 2013, Article ID 653892, 10 pages, 2013.

[34] N. Csaba, M. Köping-Höggård, and M. J. Alonso, "Ionically crosslinked chitosan/tripolyphosphate nanoparticles for oligonucleotide and plasmid DNA delivery," International Journal of Pharmaceutics, vol. 382, no. 1-2, pp. 205-214, 2009.

[35] M. E. Martin and K. G. Rice, "Peptide-guided gene delivery," The AAPS Journal, vol. 9, no. 1, article 3, pp. E18-E29, 2007.

[36] K. Buyens, B. Lucas, K. Raemdonck et al., "A fast and sensitive method for measuring the integrity of siRNA-carrier complexes in full human serum," Journal of Controlled Release, vol. 126, no. 1, pp. 67-76, 2008.

[37] J. Haupenthal, C. Baehr, S. Kiermayer, S. Zeuzem, and A. Piiper, "Inhibition of RNAse A family enzymes prevents degradation and loss of silencing activity of siRNAs in serum," Biochemical Pharmacology, vol. 71, no. 5, pp. 702-710, 2006.

[38] S. Rodrigues, A. M. R. da Costa, and A. Grenha, "Chitosan/ carrageenan nanoparticles: effect of cross-linking with tripolyphosphate and charge ratios," Carbohydrate Polymers, vol. 89, no. 1, pp. 282-289, 2012.

[39] K. S. Soppimath, T. M. Aminabhavi, A. R. Kulkarni, and W. E. Rudzinski, "Biodegradable polymeric nanoparticles as drug delivery devices," Journal of Controlled Release, vol. 70, no. 1-2, pp. 1-20, 2001.

[40] W.-J. Yi, J. Yang, C. Li et al., "Enhanced nuclear import and transfection efficiency of TAT peptide-based gene delivery systems modified by additional nuclear localization signals," Bioconjugate Chemistry, vol. 23, no. 1, pp. 125-134, 2012.

[41] R. P. Hickerson, A. V. Vlassov, Q. Wang et al., "Stability study of unmodified siRNA and relevance to clinical use," Oligonucleotides, vol. 18, no. 4, pp. 345-354, 2008.

[42] Y. Xu, Z. Wen, and Z. Xu, "Chitosan nanoparticles inhibit the growth of human hepatocellular carcinoma xenografts through an antiangiogenic mechanism," Anticancer Research, vol. 29, no. 12, pp. 5103-5109, 2009.

[43] K. J. Kim, B. Li, J. Winer et al., "Inhibition of vascular endothelial growth factor-induced angiogenesis suppresses tumour growth in vivo," Nature, vol. 362, no. 6423, pp. 841-844, 1993.
[44] R. Savić, L. Luo, A. Eisenberg, and D. Maysinger, "Micellar nanocontainers distribute to defined cytoplasmic organelles," Science, vol. 300, no. 5619, pp. 615-618, 2003.

[45] J. M. Kelm, N. E. Timmins, C. J. Brown, M. Fussenegger, and L. K. Nielsen, "Method for generation of homogeneous multicellular tumor spheroids applicable to a wide variety of cell types," Biotechnology and Bioengineering, vol. 83, no. 2, pp. 173180, 2003. 

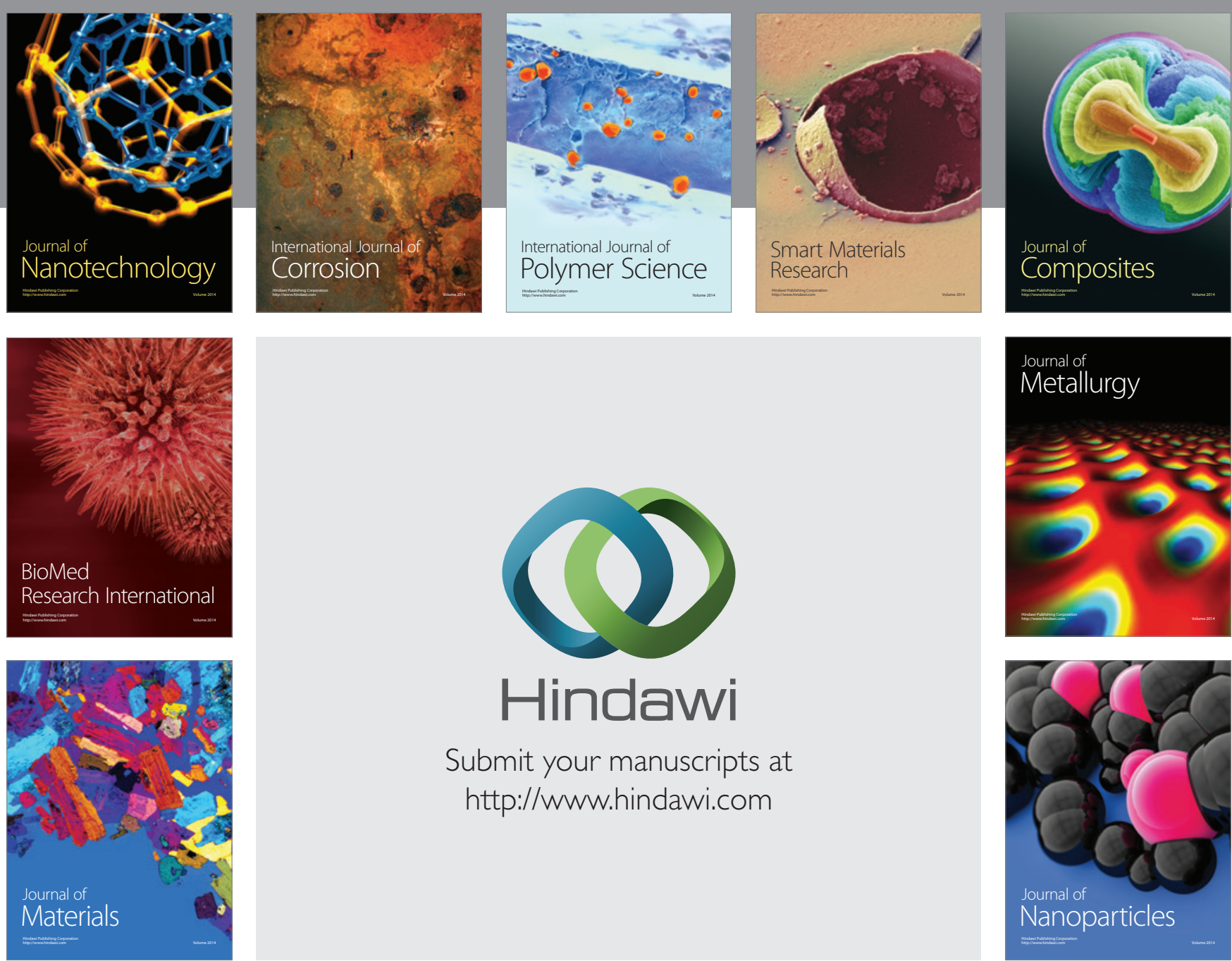

\section{Hindawi}

Submit your manuscripts at

http://www.hindawi.com

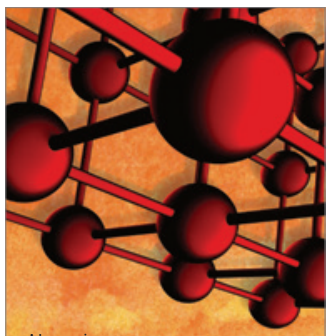

Materials Science and Engineering
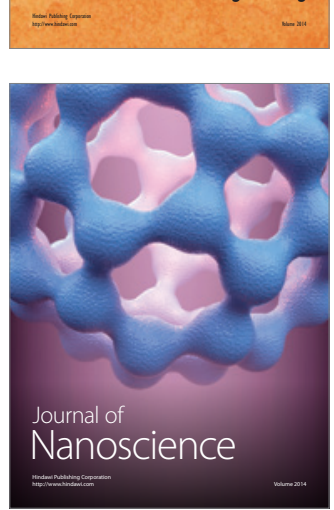
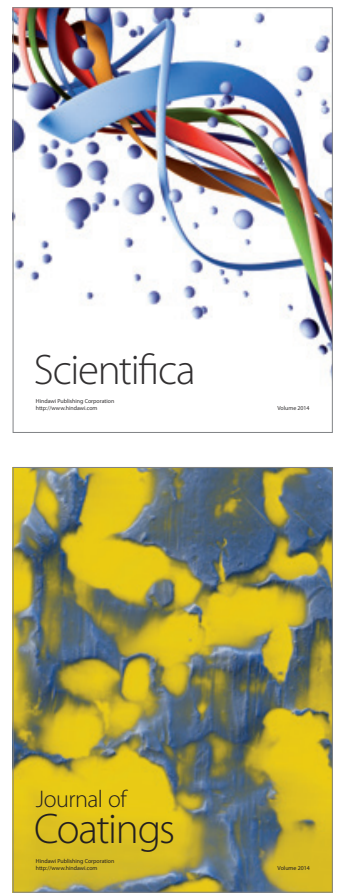
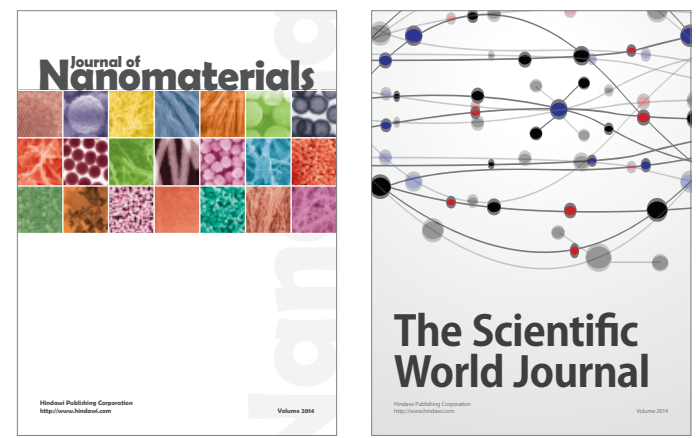

The Scientific World Journal
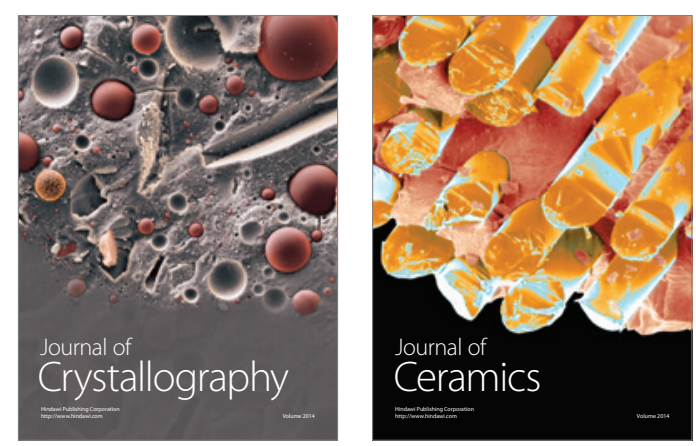
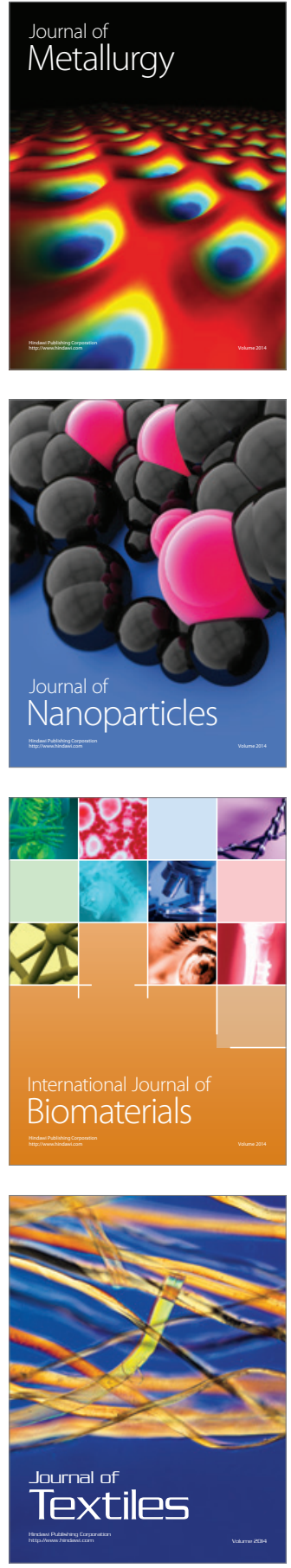